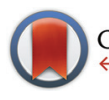

CrossMark $\leftarrow$ click for updates

Cite this: Dalton Trans., 2015, 44 11095

Received 16th January 2015

Accepted 5th May 2015

DOI: $10.1039 / c 5 d t 00213 c$

www.rsc.org/dalton

\title{
The interaction of Eu(III) with organoborates - a further approach to understand the complexation in the An/Ln(III)-borate system $\uparrow$
}

\author{
Juliane Schott, ${ }^{a, b}$ Jerome Kretzschmar, ${ }^{a}$ Satoru Tsushima, ${ }^{a}$ Björn Drobot, ${ }^{a}$ \\ Margret Acker, ${ }^{\text {b }}$ Astrid Barkleit, ${ }^{a}$ Steffen Taut, ${ }^{b}$ Vinzenz Brendler ${ }^{a}$ and \\ Thorsten Stumpf ${ }^{a, c}$
}

\begin{abstract}
The formation equilibria of salicylatoborate, lactatoborate and 3-hydroxybutyratoborate were studied by means of ${ }^{11} \mathrm{~B}$ NMR spectroscopy. The smaller the $\mathrm{p} K_{\mathrm{a}}$ of the respective organic acid, the higher is the formation constant of the organoborate. The complexation of Eu(III) with salicylatoborate and lactatoborate was investigated by means of TRLFS (time-resolved laser-induced fluorescence spectroscopy) and ${ }^{11} \mathrm{~B}$ NMR spectroscopy, yielding complexation constants $\lg \beta_{11}^{0}=2.6-3.2$. A Eu(III)-3-hydroxybutyrate complex was characterized by TRLFS and ${ }^{1} \mathrm{H}$ NMR spectroscopy $\left(\lg \beta_{11}^{0}=2.89\right)$. DFT calculations of the investigated Eu(III)-organoborates and inorganic Eu(III)-(poly)borates provided information about the Eu(III) coordination (most likely chelate). They support the hypothesis that the complexation of Eu(III) with organic as well as inorganic borate structures containing the binding site " $\mathrm{B}(\mathrm{OR})_{4}{ }^{-"}(\mathrm{R}=\mathrm{H}$, threefold coordinated boron center(s), organic moiety) is comparable.
\end{abstract}

\section{Introduction}

Great efforts have been made worldwide to find suitable environments for the safe storage of high-level radioactive wastes. In many countries it is agreed that these wastes should be stored in deep geological formations (salt, argillaceous rock, crystalline rock). Safety and risk assessment of a nuclear waste repository has to consider the case of water ingress, which would initiate corrosion and dissolution processes of the stored inventory (container material, radioactive waste), the backfill and host rock components. Trivalent actinides such as americium, curium and, under reducing conditions, plutonium, will significantly contribute to the long-term radiotoxicity of the spent nuclear fuel. ${ }^{1}$ Any reliable estimation of their migration behavior in the near and far field of such a repository requires both process understanding and data to parameterize the respective reactive transport models. In the last few decades large amounts of data concerning the chemistry of trivalent actinides, like complexation with organic and

${ }^{a}$ Helmholtz-Zentrum Dresden-Rossendorf, Institute of Resource Ecology,

Bautzner Landstraße 400, 01328 Dresden, Germany

${ }^{b}$ Technische Universität Dresden, Central Radionuclide Laboratory, 01062 Dresden, Germany.E-mail: margret.acker@tu-dresden.de

${ }^{c}$ Technische Universität Dresden, Division of Radiochemistry and Radioecology, 01062 Dresden, Germany

$\dagger$ Electronic supplementary information (ESI) available. See DOI: 10.1039/ c5dt00213c inorganic ligands as well as solubility, have been generated. Several thermodynamic databases are summarizing them. ${ }^{2-5}$ However, only recently the actinide-borate system has attracted more attention ${ }^{6-10}$ though borates are ubiquitous. In the context of nuclear waste repositories they are obtained - naturally as well as technologically - from different sources, e.g., salt deposits and brines, and corroded glass coquilles in which the high-level radioactive waste is fused. ${ }^{6,9,11}$ So far, knowledge about the complexation of (poly)borates with trivalent actinides has been insufficient in order to estimate a possible mobilization of actinides by (poly)borates in a nuclear waste repository.

Borkowski et al. investigated in their pioneering work the complexation of $\mathrm{Nd}$ (III) (as an analog for trivalent actinides) in borate solutions considering conditions typical for the Waste Isolation Pilot Plant (WIPP) near Carlsbad, New Mexico, USA. ${ }^{6}$ From solubility experiments they determined a $\mathrm{Nd}(\mathrm{III})$ borate complexation constant $\lg \beta_{11}^{0}=4.55{ }^{6}$ This complex was considered to be a predominant actinide(III) species under the WIPP brine conditions (up to $160 \mathrm{mM}$ borate, $\mathrm{pH}_{\mathrm{c}}=8-9$ ), also influencing the actinide-carbonate complexation. ${ }^{6,12}$ In a previous work, we demonstrated that the complexation constant of the trivalent europium (as another chemical analog for trivalent actinides) with (poly)borates is smaller $\left(\lg \beta_{11}^{0} \sim 2.6\right)$ than expected. ${ }^{9}$ Several difficulties (precipitation of the metal borates, metal hydroxide complexation and precipitation at higher $\mathrm{pH}$ ) made the investigation of this system very challenging. Therefore, approximations had to be made in order to 
obtain a complexation constant for the An/Ln(III)-(poly)borate system $(\mathrm{An}=$ actinide, $\mathrm{Ln}=$ lanthanide $) .{ }^{9}$

In the present work, a completely different approach was drafted to support the $\lg \beta_{11}^{(0)}$ values obtained previously for $\mathrm{Eu}(\mathrm{III})$-(poly)borate complexes ${ }^{9}$ using organoborates as structural representatives for borate compounds.

The simplest form of a borate species is the monoborate anion. Due to the high dissociation constant of boric acid ( $\mathrm{p} K_{\mathrm{a}}$ $=9.13$, our data by potentiometric titration, see below) the monoborate anion exists in considerable amounts only in the high alkaline $\mathrm{pH}$ range. There, unfortunately, complexation studies with trivalent actinides or lanthanides are next to impossible, due to the formation of strong metal hydroxide complexes, which could even precipitate. Therefore, an alternative experimental approach under acidic conditions was devised. The binding site to the metal ion is the structural unit $\mathrm{B}(\mathrm{OR})_{4}{ }^{-}$containing a fourfold coordinated boron center with a negative charge. Our hypothesis is that all borates (inorganic, organic) containing this $\mathrm{B}(\mathrm{OR})_{4}{ }^{-}$unit $(\mathrm{R}=\mathrm{H}$, other threefold coordinated boron center(s), organic moieties, thereby including also the simple monoborate anion and inorganic polyborates with one binding site) exhibit a comparable complexation behavior concerning trivalent lanthanides or actinides.

Organoborates form a group of compounds containing such a $\mathrm{B}(\mathrm{OR})_{4}^{-}$unit. The literature describes the formation of these organoborates by reactions of either boric acid with hydroxycarboxylates or the monoborate anion with polyols (Fig. 1). ${ }^{13,14}$ In contrast to the polyol based organoborates the ones based on hydroxycarboxylates are formed (and are stable) in the acidic pH range. Here, metal complexation studies can be carried out with good prospects. Hence, hydroxycarboxylate based organoborates were used to study the complexation with $\mathrm{Eu}(\mathrm{III})$.

Primarily, the objective of this work was to confirm our hypothesis experimentally investigating the complexation of $\mathrm{Eu}(\mathrm{III})$ with different organoborates. Namely, we wanted to know to what extent the ring size (five- and six-membered) of the respective organoborate and the nature of the organic moiety bound to the $\mathrm{B}(\mathrm{OR})_{4}{ }^{-}$unit influence the $\mathrm{Eu}(\mathrm{III})$ complexation. Consequently, for the first time different $\mathrm{Eu}(\mathrm{III})-$

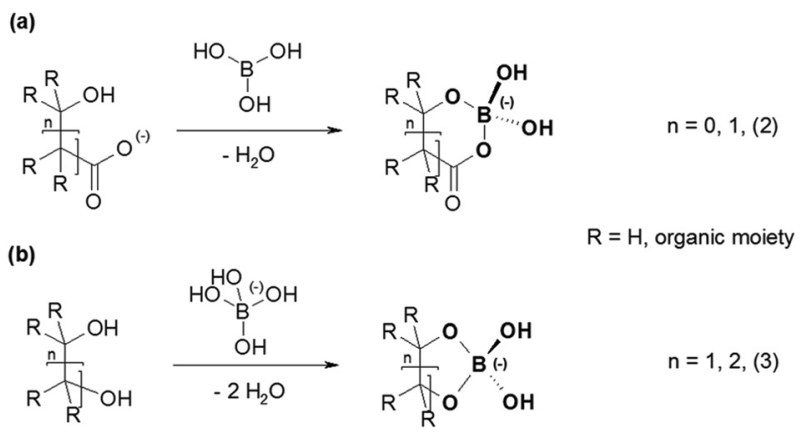

Fig. 1 General structures of organoborates resulting from the reaction of (a) boric acid with hydroxycarboxylates and (b) the monoborate anion with polyols. organoborate complexes are described with specific thermodynamic values.

Salicylatoborate, lactatoborate and 3-hydroxybutyratoborate were chosen as complexing organic borate ligands (Fig. S1†). Because the complexation reactions of $\mathrm{Eu}(\mathrm{III})$ with the (pure) carboxylates have to be considered in the calculation of the $\mathrm{Eu}(\mathrm{III})$-organoborate complex formation constants, it is of advantage that these reactions with the chosen carboxylates are well characterized.

By TRLFS (time-resolved laser-induced fluorescence spectroscopy) and ${ }^{11} \mathrm{~B}$ NMR (nuclear magnetic resonance) spectroscopy we were able to study the $\mathrm{Eu}(\mathrm{III})$-organoborate complexation from two opposite perspectives: TRLFS probes the metal site, where changes in the Eu(III) speciation can be observed with high sensitivity and selectivity at low metal concentrations $\left(\sim 10^{-5} \mathrm{M}\right)$, whereas NMR provides a view of the ligand (organoborate) and its speciation changes in the presence of Eu(III). Due to the paramagnetism of $\mathrm{Eu}^{3+}$, the signals of molecules interacting with the europium ion are shifted considerably with only low signal broadening. ${ }^{15-17}$ The Eu(III) concentration dependent paramagnetic induced shift ${ }^{18}$ was used here to determine the complexation constant of the $\mathrm{Eu}(\mathrm{III})$-salicylatoborate and $\mathrm{Eu}(\mathrm{III})-$ lactatoborate.

Density functional theory (DFT) calculations are useful to test the hypothesis that borates with the structural unit $\mathrm{B}(\mathrm{OR})_{4}^{-}$have comparable complexation properties to $\mathrm{An} / \mathrm{Ln}(\mathrm{III})$. Therefore, in this work different borate structures (inorganic (poly)borates, organoborates) and the respective $\mathrm{Eu}(\mathrm{III})$ complex structures were calculated. This also provided further insights into the coordination of $\mathrm{Eu}(\mathrm{III})$ with the borate structures.

One prerequisite for the $\mathrm{Eu}(\mathrm{III})$ organoborate complexation studies is the $\mathrm{p} K_{\mathrm{a}}$ values of the organic compounds used (salicylic, lactic and 3-hydroxybutyric acid) and boric acid. They were determined by potentiometric titration. Furthermore, the formation constants of the organoborates were obtained from ${ }^{11} \mathrm{~B}$ NMR experiments. The Eu(III)-salicylate and Eu(III)-lactate complexation constants were determined by TRLFS or obtained from the literature. A complexation constant for the 1:1 Eu(III)-3-hydroxybutyrate complex was determined from TRLFS and ${ }^{1} \mathrm{H}$ NMR spectroscopic data.

\section{Experimental section}

\section{Chemicals and materials}

Solutions were prepared from chemicals of analytical grade and deionized water. Sodium salicylate (Sigma Aldrich), sodium L-lactate (Sigma Aldrich), sodium D/L-3-hydroxybutyrate (Fluka) and boric acid (Merck) were used without further purification. The total boron concentration $\left(c_{\mathrm{B}, \text { total }}\right)$ was adjusted with boric acid. A Eu(III) stock solution $(30 \mathrm{mM})$ was prepared by dissolving $\mathrm{Eu}_{2} \mathrm{O}_{3}$ (Aldrich) in $0.1 \mathrm{M} \mathrm{HClO}_{4}$. Its concentration was verified by ICP-MS (Elan 9000, Perkin Elmer). Solid $\mathrm{EuCl}_{3} \cdot 6 \mathrm{H}_{2} \mathrm{O}$ (Aldrich) was used to adjust higher Eu(III) concentrations (up to $50 \mathrm{mM}$ ). All samples for potentiometric titration 
and TRLFS experiments were prepared at $0.1 \mathrm{M}$ ionic strength $\left(\mathrm{NaClO}_{4}\right.$ (Merck)). The $\mathrm{pH}$ measurements (adjustment, potentiometric titration) were carried out with glass electrodes (SCHOTT) calibrated with buffer solutions (NIST/PTB standard buffers). The $\mathrm{pH}$ of the solutions was adjusted with $\mathrm{NaOH}$ or $\mathrm{HClO}_{4}$ (Merck).

\section{Determination of $\mathrm{pK}_{\mathrm{a}}$ of boric, salicylic, lactic and 3-hydroxybutyric acid}

Potentiometric titration series were carried out with solutions containing varying concentrations of boric acid, salicylate, lactate or 3-hydroxybutyrate prepared at $\sim \mathrm{pH} 2$ under ambient conditions $\left(T=22^{\circ} \mathrm{C}, p_{\mathrm{CO}_{2}}=10^{-3.5}\right.$ bar). $20 \mathrm{~mL}$ of each solution were automatically titrated (736 GP Titrino/TiNet 2.50, Metrohm) up to $\mathrm{pH} 12$ under a $\mathrm{N}_{2}$-atmosphere in a temperature adjustable titration vessel at $22{ }^{\circ} \mathrm{C}$ by adding $0.1 \mathrm{M} \mathrm{NaOH}$ (carbonate-free). The dynamic titration procedure was used. 60 seconds after adding $\mathrm{NaOH}$ the $\mathrm{pH}$ measurements were initiated.

\section{Formation of organoborates}

Solutions with varying total organic (salicylate/lactate/3-hydroxybutyrate) and total boron concentrations were prepared at $\mathrm{pH} 5$ under ambient conditions one day prior to the ${ }^{11} \mathrm{~B}$ NMR measurements. The total boron concentration was used in large excess so that the 1:1 organoborate compound is formed exclusively. Any polyborate formation is negligible under these $\mathrm{pH}$ conditions in both the salicylatoborate and lactatoborate systems. $^{9}$

Eu(III) complexation by salicylate and 3-hydroxybutyrate (3-HB)

For the TRLFS studies solutions with varying total salicylate/ 3-HB concentrations were prepared at pH 5.5 under ambient conditions. $2 \mathrm{~mL}$ of each solution were transferred into a quartz cuvette. $2 \mu \mathrm{L}$ of the $30 \mathrm{mM} \mathrm{Eu(III)} \mathrm{stock} \mathrm{solution}$ were added to this volume to set total Eu(III) concentration as $3 \times 10^{-5} \mathrm{M}$. The samples were titrated from $\mathrm{pH} 5.5$ down to around $\mathrm{pH} 2$ by adding appropriate amounts of $\mathrm{HClO}_{4}$. After each titration step a stationary europium TRLFS spectrum was recorded.

For the ${ }^{1} \mathrm{H}$ NMR measurements solutions with a constant $5 \mathrm{mM}$ total 3 -HB concentration were prepared at $\mathrm{pH} 5.17$ under ambient conditions before adding appropriate amounts of $\mathrm{EuCl}_{3} \cdot 6 \mathrm{H}_{2} \mathrm{O}$ to adjust up to $50 \mathrm{mM}$ total $\mathrm{Eu}$ (III) concentration.

\section{Eu(III)-organoborate complexation studies}

For the TRLFS studies solutions with varying total organic (salicylate/lactate) and total boron concentrations were prepared at $\mathrm{pH} 4.4$ under ambient conditions. The total boron concentration was adjusted up to $0.4 \mathrm{M}$ to provide high-level conversion of the organic compound into the respective organoborate. The formation of polyborates can be excluded under such experimental conditions. ${ }^{9}$ One day after the solution preparation, $2 \mathrm{~mL}$ of a solution with adjusted total organic and boron concentrations was transferred into a quartz cuvette. $2 \mu \mathrm{L}$ of the $30 \mathrm{mM} \mathrm{Eu}(\mathrm{III})$ stock solution was added to this volume to adjust the total $\mathrm{Eu}(\mathrm{III})$ concentration to $3 \times 10^{-5} \mathrm{M}$. The samples were titrated from $\mathrm{pH} 4.4$ down to around $\mathrm{pH} 2$ by adding appropriate amounts of $\mathrm{HClO}_{4}$. After each titration step the stationary and, in some cases, also the time-resolved europium luminescence spectra were recorded.

For the ${ }^{11} \mathrm{~B}$ NMR measurements solutions with a constant total organic concentration ( $5 \mathrm{mM}$ or $10 \mathrm{mM}$ salicylate; $5 \mathrm{mM}$ lactate) and a total boron concentration (200 mM) were prepared at $\mathrm{pH} 5$ under ambient conditions one day prior to the addition of appropriate amounts of $\mathrm{EuCl}_{3} \cdot 6 \mathrm{H}_{2} \mathrm{O}$ to adjust up to $50 \mathrm{mM}$ total $\mathrm{Eu}(\mathrm{III})$ concentration.

\section{Nuclear magnetic resonance (NMR) spectroscopy}

The NMR spectra of the $10 \mathrm{mM}$ salicylate solution series were recorded on a Varian Unity Inova 400 spectrometer with a field strength of $9.4 \mathrm{~T}$, corresponding to a ${ }^{11} \mathrm{~B}$ resonance frequency of $128.4 \mathrm{MHz}$, using a $5 \mathrm{~mm}$ direct detection broadband probe. The spectra of the $5 \mathrm{mM}$ salicylate, lactate, and 3-hydroxybutyrate series were recorded on an Agilent DD2-600 $\mathrm{MHz}$ NMR system, operating at $14.1 \mathrm{~T}$ with the corresponding ${ }^{1} \mathrm{H}$ and ${ }^{11} \mathrm{~B}$ resonance frequencies of 599.8 and $192.4 \mathrm{MHz}$, respectively, using a $5 \mathrm{~mm}$ broadband (OneNMR ${ }^{\mathrm{TM}}$ ) probe and a quarter-wave switch for ${ }^{11} \mathrm{~B}$. As an experimental setup the $5 \mathrm{~mm}$ NMR tube (quartz) containing the aqueous $\left(\mathrm{H}_{2} \mathrm{O}\right)$ solution was equipped with a $\mathrm{D}_{2} \mathrm{O}$ filled coaxial quartz insert for a deuterium lock. As the investigations were performed in $\mathrm{H}_{2} \mathrm{O}$, suppression of the ${ }^{1} \mathrm{H}$ water signal was mandatory, and achieved by a presaturation pulse sequence, applying a $2 \mathrm{~s}$ presaturation pulse with an offset on resonance of the water signal frequency (varying with the Eu(III) concentration) prior to the detection pulse. For ${ }^{1} \mathrm{H}$ and ${ }^{11} \mathrm{~B}$ experiments the measurements were quantitatively obtained by application of $\pi / 6$ and $\pi / 2$ pulses, respectively, and relaxation delays $\geq 5 \times T_{1}$, the latter being shortened with increasing Eu(III) concentration. ${ }^{1} \mathrm{H}$ and ${ }^{11} \mathrm{~B}$ chemical shifts $(\delta)$ are referenced externally with respect to TMS (tetramethylsilane) in $\mathrm{CDCl}_{3}$ and $\mathrm{BF}_{3}$ etherate in $\mathrm{CDCl}_{3}$, respectively.

\section{Time-resolved laser-induced fluorescence spectroscopy (TRLFS)}

A Nd:YAG-OPO laser system (Continuum) was used for the TRLFS measurements of the europium containing solutions. The solutions were stirred and stationary as well as timeresolved europium spectra were recorded with an excitation wavelength of $394 \mathrm{~nm}$, a constant time window of $1 \mathrm{~ms}$, a pulse energy of 2-3 $\mathrm{mJ}$ and an optical multichannel analyzer (spectrograph (Oriel MS 257) and ICCD camera (Andor iStar)). Stationary spectra were recorded under the following conditions: wavelength detection range 565-650 nm, 1200 lines per $\mathrm{mm}$ grating ( $0.2 \mathrm{~nm}$ resolution), and 3000 accumulations. Time-resolved spectra were recorded under the following conditions: wavelength detection range 440-780 nm, 300 lines per $\mathrm{mm}$ grating (0.7 $\mathrm{nm}$ resolution), 100 accumulations, and delay time steps $15-40 \mu \mathrm{s}$. 


\section{Density functional theory (DFT) calculations}

DFT calculations of organic and inorganic borate structures and respective $\mathrm{Eu}(\mathrm{III})$ complexes were performed using the Gaussian $09^{19}$ program. Geometries were optimized in the aqueous phase at the B3LYP level using the CPCM solvation model with UAHF radii. ${ }^{20}$ Two additional DFT functionals, namely TPSSh and PBE0, were tested for organic and inorganic borate complexes without europium. ${ }^{11} \mathrm{~B}$ NMR spectra were calculated using the optimized geometry. The large core effective core potential (LC-ECP) as well as the corresponding basis set suggested by Dolg et $a .^{21}$ was used for europium. For O, C, B, and $\mathrm{H}$, all-electron valence triple- $\zeta$ basis set plus polarization and diffuse functions ${ }^{22}$ have been used. More details of the DFT calculations are described in our previous publication. ${ }^{23}$

\section{Data analysis}

The following chemical reactions were considered for the subsequent analysis procedures, eqn (1a)-(f):

$$
\begin{gathered}
\mathrm{LH} \rightleftharpoons \mathrm{L}^{-}+\mathrm{H}^{+} \quad K_{\mathrm{a}, \mathrm{LH}}=\frac{\left[\mathrm{L}^{-}\right]\left[\mathrm{H}^{+}\right]}{[\mathrm{LH}]} \\
\mathrm{BH}+\mathrm{H}_{2} \mathrm{O} \rightleftharpoons \mathrm{B}^{-}+\mathrm{H}^{+} \quad K_{\mathrm{a}, \mathrm{BH}}=\frac{\left[\mathrm{B}^{-}\right]\left[\mathrm{H}^{+}\right]}{[\mathrm{BH}]} \\
\mathrm{BH}+\mathrm{L}^{-} \rightleftharpoons \mathrm{BL}^{-}+\mathrm{H}_{2} \mathrm{O} \quad K_{\mathrm{BL}}=\frac{\left[\mathrm{BL}^{-}\right]}{[\mathrm{BH}]\left[\mathrm{L}^{-}\right]} \\
\mathrm{Eu}^{3+}+\mathrm{L}^{-} \rightleftharpoons \mathrm{EuL}^{2+} \quad \beta_{\mathrm{EuL}}=\frac{\left[\mathrm{EuL}^{2+}\right]}{\left[\mathrm{Eu}^{3+}\right]\left[\mathrm{L}^{-}\right]} \\
\mathrm{Eu}^{3+}+2 \mathrm{~L}^{-} \rightleftharpoons \mathrm{EuL}_{2}^{+} \quad \beta_{\mathrm{EuL} 2}=\frac{\left[\mathrm{EuL}_{2}^{+}\right]}{\left[\mathrm{Eu}^{3+}\right]\left[\mathrm{L}^{-}\right]^{2}} \\
\mathrm{Eu}^{3+}+\mathrm{BL}^{-} \rightleftharpoons \mathrm{Eu}(\mathrm{BL})^{2+} \quad \beta_{\mathrm{Eu}(\mathrm{BL})}=\frac{\left[{\left.\mathrm{Eu}(\mathrm{BL})^{2+}\right]}_{\left[\mathrm{Eu}^{3+}\right]\left[\mathrm{BL}^{-}\right]}\right.}{}
\end{gathered}
$$

where $\mathrm{LH}=$ organic acid (salicylic, lactic or 3-hydroxybutyric acid), $\mathrm{L}^{-}=$deprotonated organic acid (salicylate (Sal), lactate (Lac), 3-hydroxybutyrate (3-HB)), $\mathrm{BH}=$ boric acid, $\mathrm{B}^{-}=$deprotonated boric acid (monoborate), $\mathrm{BL}^{-}=$organoborate (salicylatoborate (BSal), lactatoborate (BLac), 3-hydroxybutyratoborate (B-3-HB)), $\mathrm{EuL}^{2+}=1: 1 \mathrm{Eu}(\mathrm{III})$-organic complex (Eu(III)-salicylate (Eu-Sal), Eu(III)-lactate (Eu-Lac), Eu(III)-3-hydroxybutyrate $(\mathrm{Eu}-3-\mathrm{HB})), \mathrm{EuL}_{2}{ }^{+}=1: 2 \mathrm{Eu}(\mathrm{III})$-organic complex, Eu(BL $)^{2+}=$ $1: 1 \mathrm{Eu}(\mathrm{III})$-organoborate complex (Eu(III)-salicylatoborate (EuBSal), Eu(III)-lactatoborate (Eu-BLac)), $K_{\mathrm{a}}=$ acid dissociation constant, $K_{\mathrm{BL}}=$ formation constant of organoborate, $\beta=$ complexation constant.

The $\mathrm{p} K_{\mathrm{a}}$ values of the organic acids and boric acid were calculated from the potentiometric titration data by means of the software Hyperquad2008. ${ }^{24}$ Applications of this software are demonstrated elsewhere. ${ }^{25-27}$

The organoborate formation constants $K_{\mathrm{BL}}$ were calculated from ${ }^{11} \mathrm{~B}$ NMR data by means of the software HySS, version 4.0.31. ${ }^{28} K_{\mathrm{BL}}$ were iteratively determined by varying the $K_{\mathrm{BL}}$ value until the calculated free boric acid and organoborate concentrations were equal to those determined by ${ }^{11} \mathrm{~B} \mathrm{NMR}$ spectroscopy (integrating the concentration proportional ${ }^{11} \mathrm{~B}$ signal areas).

The complexation constants of the $\mathrm{Eu}(\mathrm{III})$-organoborate complexes $\beta_{\mathrm{Eu}(\mathrm{BL})}$ were calculated from ${ }^{11} \mathrm{~B}$ NMR spectroscopic data by analyzing the Eu(III) concentration dependent chemical shift, $\delta_{\text {obs }}$, of the organoborate (Fig. 2, and S2 $\dagger$ ).

The observed ${ }^{11} \mathrm{~B}$ chemical shift of the organoborate signal, $\delta_{\text {obs }}$, is an average of the chemical shifts of the free and $\mathrm{Eu}(\mathrm{III})$ bound organoborate weighed by their respective molar fractions (fast exchange approximation). In addition, a contribution of the bulk susceptibility $\left(\Delta \delta_{\text {susc }}\right)$ increasingly enhanced due to the rising Eu(III) concentration has to be considered, eqn (2a).

$$
\delta_{\mathrm{obs}}=\sum_{i} x_{i} \delta_{i}+\Delta \delta_{\mathrm{susc}}
$$

It is assumed that the bulk susceptibility affects all components - organoborates, free boric acid and solvent - equally and isotropically. After subtraction of the bulk susceptibility contribution term, $\Delta \delta_{\text {susc }}$, the effective signal position, $\delta_{\text {obs }}^{*}$, of the organoborate was obtained, eqn (2b.1) and (2b.2). $\Delta \delta_{\text {susc }}$ can be estimated from chemical shift changes of signals of molecules that virtually do not interact with $\mathrm{Eu}(\mathrm{III})$, such as $\mathrm{B}(\mathrm{OH})_{3}$ and bulk $\mathrm{H}_{2} \mathrm{O}$. These changes are due to the difference in the ${ }^{11} \mathrm{~B}$ and ${ }^{1} \mathrm{H}$ chemical shifts of the $\mathrm{B}(\mathrm{OH})_{3}$ and $\mathrm{H}_{2} \mathrm{O}$ signals, respectively, in the respective $\mathrm{Eu}(\mathrm{III})$ containing systems $\left(\delta_{\mathrm{B}(\mathrm{OH})_{3}}\right.$ or $\left.\delta_{\mathrm{H}_{2} \mathrm{O}}\right)$ and the $\mathrm{Eu}(\mathrm{III})$ free system $\left(\delta_{\mathrm{B}(\mathrm{OH})_{3}}^{\#}\right.$ or $\left.\delta_{\mathrm{H}_{2} \mathrm{O}}^{\#}\right)$.

$$
\delta_{\mathrm{obs}}^{*}=\delta_{\mathrm{obs}}-\left(\delta_{\mathrm{B}(\mathrm{OH})_{3}}-\delta_{\mathrm{B}(\mathrm{OH})_{3}}^{\#}\right) \text { for }{ }^{11} \mathrm{~B} \mathrm{NMR}
$$

or

$$
\delta_{\mathrm{obs}}^{*}=\delta_{\mathrm{obs}}-\left(\delta_{\mathrm{H}_{2} \mathrm{O}}-\delta_{\mathrm{H}_{2} \mathrm{O}}^{\#}\right) \quad \text { for }{ }^{1} \mathrm{H} \mathrm{NMR}
$$

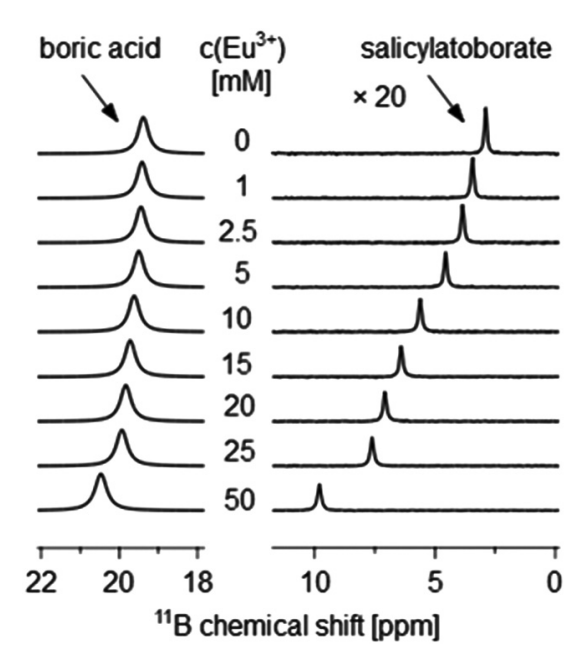

Fig. $2{ }^{11} \mathrm{~B}$ NMR spectra of aqueous solutions at $\mathrm{pH} 5$ containing $5 \mathrm{mM}$ salicylate, $200 \mathrm{mM}$ total boron and varying Eu(III) concentrations as indicated; salicylatoborate signals enhanced by a factor of 20 . 
In conclusion $\delta_{\mathrm{obs}}^{*}$ is expressed as follows (eqn (2c)) according to eqn (2a):

$$
\delta_{\text {obs }}^{*}=x_{\text {free }} \delta_{\text {free }}+x_{\text {complex }} \delta_{\text {complex }}^{*}=x_{\text {free }} \delta_{\text {free }}+\left(1-x_{\text {free }}\right) \delta_{\text {complex }}^{*}
$$

The ${ }^{11} \mathrm{~B}$ chemical shift of the organoborate, $\delta_{\text {free, was }}$ obtained from the ${ }^{11} \mathrm{~B}$ NMR spectrum of the $\mathrm{Eu}(\mathrm{III})$ free organoborate solution. The ${ }^{11} \mathrm{~B}$ chemical shift of the completely Eu(III) bound organoborate, $\delta_{\text {complex }}^{*}$, was determined by fitting the corrected data points $\delta_{\text {obs }}^{*}$ by an asymptotic function of the $\mathrm{Eu}(\mathrm{III})$ concentration (Fig. 3 and S $3 \dagger$ ). The limit of this function at infinite $\mathrm{Eu}(\mathrm{III})$ concentrations represents $\delta_{\text {complex}}^{*}$ An example for the determination of $\delta_{\text {complex }}^{*}$ via the asymptotic fit is shown in Fig. 3. The values of $\delta_{\text {free }}$ and $\delta_{\text {complex }}^{*}$ for BSal and BLac are summarized in Table 1 . From the ${ }^{11} \mathrm{~B}$ NMR signal positions of the organoborate, $\delta_{\text {obs }}^{*}$, the mole fraction $x$ of free and Eu(III) bound organoborates was deduced, eqn (2d) and (2e).

$$
\begin{gathered}
x_{\text {free }}=\frac{\delta_{\text {obs }}^{*}-\delta_{\text {complex }}^{*}}{\delta_{\text {free }}-\delta_{\text {complex }}^{*}} \\
x_{\text {complex }}=1-x_{\text {free }}
\end{gathered}
$$

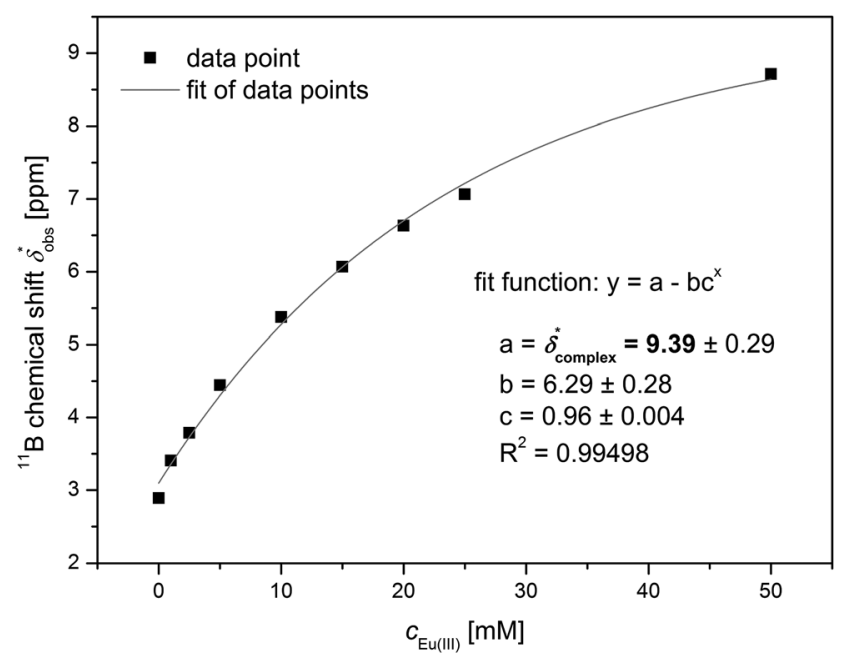

Fig. 3 Determination of $\delta_{\text {complex }}^{*}$ of the Eu(III) salicylatoborate complex from ${ }^{11} \mathrm{~B}$ NMR spectroscopic data $(5 \mathrm{mM}$ salicylate, $200 \mathrm{mM}$ total boron, varying $\mathrm{Eu}(\mathrm{III})$ concentrations).

Table 1 Values for $\delta_{\text {free }}$ and $\delta_{\text {complex }}^{*}$ of the investigated organoborates

\begin{tabular}{llllr}
\hline Organoborate & $\begin{array}{l}c_{\text {organic,total }} \\
{[\mathrm{mM}]}\end{array}$ & $\begin{array}{l}c_{\mathrm{B}, \text { total }} \\
{[\mathrm{mM}]}\end{array}$ & $\begin{array}{l}\delta_{\text {free }} \\
{[\mathrm{ppm}]}\end{array}$ & \multicolumn{1}{c}{$\begin{array}{l}\delta_{\text {complex }}^{*} \\
{[\mathrm{ppm}]}\end{array}$} \\
\hline BSal & 5 & 200 & 2.9 & $9.4( \pm 0.3)$ \\
BSal & 10 & 200 & 2.9 & $9.2( \pm 0.4)$ \\
BLac & 5 & 200 & 6.3 & $26.3( \pm 4.8)$
\end{tabular}

With the information of the fractions of free $\left(x_{\text {free }}\right)$ and $\mathrm{Eu}(\mathrm{III})$ bound organoborates $\left(x_{\text {complex }}\right)$ complexation constants were determined by the described iterative procedure using the speciation program HySS. ${ }^{28}$ The complexation constant of the $\mathrm{Eu}(\mathrm{III})$-organoborate in the speciation model was varied until the calculated free and Eu(III) bound organoborate concentrations are equal to those determined by ${ }^{11} \mathrm{~B}$ NMR spectroscopy.

In a similar way $\beta_{\mathrm{Eu}(3-\mathrm{HB})}$ was determined from ${ }^{1} \mathrm{H}$ NMR spectroscopic data (Fig. S4 and $55 \dagger$ ). The ${ }^{1} \mathrm{H}$ chemical shifts of $3-\mathrm{HB}, \delta_{\text {free }}\left(\mathrm{CH}-\mathrm{OH} / \mathrm{CH}_{2} / \mathrm{CH}_{3}\right)$, were obtained from the $\mathrm{Eu}(\mathrm{III})$ free 3 -HB solution (Fig. S4 $\dagger$ ). The ${ }^{1} \mathrm{H}$ chemical shifts of the completely $\mathrm{Eu}(\mathrm{III})$ bound $3-\mathrm{HB}, \delta_{\text {complex }}^{*}\left(\mathrm{CH}-\mathrm{OH} / \mathrm{CH}_{2} / \mathrm{CH}_{3}\right)$, were determined by plotting $\delta_{\text {obs }}^{*}\left(\mathrm{CH}-\mathrm{OH} / \mathrm{CH}_{2} / \mathbf{C H}_{3}\right)$ vs. the $\mathrm{Eu}(\mathrm{III})$ concentration (Fig. S5 $\dagger$ ). $\delta_{\mathrm{obs}}^{*}\left(\mathrm{CH}-\mathrm{OH} / \mathrm{CH}_{2} / \mathrm{CH}_{3}\right)$ was obtained by correcting $\delta_{\text {obs }}\left(\mathrm{CH}-\mathrm{OH} / \mathrm{CH}_{2} / \mathrm{CH}_{3}\right)$ with $\Delta \delta_{\text {susc }}$ of bulk water (eqn (2b.2)). The corrected data points were fitted by an asymptotic function (Fig. S5 $\dagger$ ). The values of $\delta_{\text {free }}(\mathbf{C H}-$ $\left.\mathrm{OH} / \mathbf{C H}_{2} / \mathbf{C H}_{3}\right)$ and $\delta_{\text {complex }}^{*}\left(\mathbf{C H}-\mathrm{OH} / \mathbf{C H}_{2} / \mathbf{C H}_{3}\right)$ for $3-\mathrm{HB}$ are summarized in Table $\mathrm{S} 1 . \dagger$ With the information of the fractions of free $\left(x_{\text {free }}\left(\mathrm{CH}-\mathrm{OH} / \mathrm{CH}_{2} / \mathrm{CH}_{3}\right)\right)$ and $\mathrm{Eu}(\mathrm{III})$ bound $3-\mathrm{HB}$ $\left(x_{\text {complex }}\left(\mathrm{CH}-\mathrm{OH} / \mathrm{CH}_{2} / \mathrm{CH}_{3}\right)\right)$, Table $\mathrm{S} 1, \dagger$ a complexation constant for the 1:1 Eu(III)-3-hydroxybutyrate complex was determined by the described iterative procedure (see above) using the program HySS. ${ }^{28}$

Usually, europium luminescence spectra are analyzed in terms of ${ }^{5} \mathrm{D}_{0} \rightarrow{ }^{7} \mathrm{~F}_{0}$ (at $\sim 578 \mathrm{~nm}$; forbidden for the europium aqua ion $\left(\mathrm{Eu}(\mathrm{III})_{\mathrm{aq}}\right.$ )), ${ }^{5} \mathrm{D}_{0} \rightarrow{ }^{7} \mathrm{~F}_{1}$ (at $\sim 592 \mathrm{~nm}$ ) and ${ }^{5} \mathrm{D}_{0} \rightarrow{ }^{7} \mathrm{~F}_{2}$ (at $\sim 616 \mathrm{~nm}$ ) transition bands. The analysis of the TRLFS spectra was carried out using the software Origin ${ }^{\mathrm{TM}}$ (version 7.5G, OriginLab Corporation). Stationary and time-resolved raw spectra were baseline corrected. In addition, the stationary spectra were normalized to the ${ }^{5} \mathrm{D}_{0} \rightarrow{ }^{7} \mathrm{~F}_{1}$ transition, because the luminescence intensity caused by this transition is independent of the chemical environment of europium. ${ }^{29}$ The timeresolved luminescence spectra of the Eu(III)-organoborate complexation systems were analyzed by parallel factor analysis (PARAFAC), ${ }^{30}$ successfully applied before in a broad variety of research fields, ${ }^{31-34}$ and in the inorganic $\mathrm{Eu}(\mathrm{III})$-(poly)borate complexation system. ${ }^{9}$ From PARAFAC the luminescence lifetimes of pure Eu(III) species and Eu(III) species distributions were obtained. The Eu(III) speciation serves as a basis to calculate the complexation constant for the $\mathrm{Eu}(\mathrm{III})$-organoborate complexes. The complexation constant was determined by the described iterative procedure (see above) using the program HySS. $^{28}$ The stationary TRLFS data from the $\mathrm{pH}$ titration series to determine the complexation constants of the Eu-Sal complex $\beta_{\text {EuSal }}$ and Eu-3-HB complex $\beta_{\mathrm{Eu}(3-\mathrm{HB})}$ as well as the complexation constants of the Eu-BSal complex $\beta_{\mathrm{Eu}(\mathrm{BSal})}$ were analyzed using the software HypSpec. ${ }^{35}$ Applications of this software can be found in various studies. ${ }^{36-39}$

Our determined values of $\mathrm{p} K_{\mathrm{a}}, \lg K_{\mathrm{BL}}$ and $\lg \beta$ were extrapolated to infinite dilution, following the extended DebyeHückel approach as published by Davies, $1962 .{ }^{40}$

Throughout the paper all given uncertainties correspond to $2 \sigma$, i.e., the $95 \%$ confidence level. 


\section{Results and discussion}

\section{Determination of $\mathrm{pK}_{\mathrm{a}}$ of organic acids and boric acid}

The determined $\mathrm{p} K_{\mathrm{a}}$ values of salicylic, lactic, 3-hydroxybutyric and boric acid are summarized in Table 2, showing good agreement with the literature data (Table 2). The $\mathrm{p} K_{\mathrm{a}}$ values are required for the calculation of $\beta_{\mathrm{EuL}}, K_{\mathrm{BL}}$ and $\beta_{\mathrm{Eu}(\mathrm{BL})}$ as described in the subsequent sections.

\section{Formation of organoborates}

For the theoretical considerations the solution structures of BSal and BLac were optimized at the B3LYP level and are presented in Fig. $4 \mathrm{a}$ and b. For comparison of the $\mathrm{B}(\mathrm{OR})_{4}{ }^{-}$unit in different borate compounds (inorganic, organic), and discussion of the hypothesis later on, the solution structures of triborate $\left(\mathrm{B}_{3} \mathrm{O}_{3}(\mathrm{OH})_{4}{ }^{-}\right)$, pentaborate $\left(\mathrm{B}_{5} \mathrm{O}_{6}(\mathrm{OH})_{4}{ }^{-}\right)$and monoborate $\left(\mathrm{B}(\mathrm{OH})_{4}{ }^{-}\right)$were also calculated and are shown in Fig. $4 \mathrm{c}-\mathrm{e}$.

Table $2 \mathrm{p} K_{\mathrm{a}}$ values of organic acids and boric acid, determined within this work $\left(T=22{ }^{\circ} \mathrm{C}\right.$, bold text) in comparison with the literature $(T=$ $\left.25^{\circ} \mathrm{C}\right)$; deviation: $2 \sigma$

\begin{tabular}{lll}
\hline LH & $\mathrm{p} K_{\mathrm{a}}(I=0.1 \mathrm{M})$ & $\mathrm{p} K_{\mathrm{a}}^{0}(I=0)^{a}$ \\
\hline Salicylic acid & $2.83 \pm \mathbf{0 . 0 4}$ & $\mathbf{3 . 0 4} \pm \mathbf{0 . 0 4}$ \\
Lactic acid & $2.77,{ }^{41} 2.81,{ }^{42} 2.82^{43}$ & \\
& $3.73 \pm 0.01$ & $3.94 \pm 0.01$ \\
3-Hydroxybutyric acid & $3.62^{44}, 3.69^{45}, 3.77^{46}$ & \\
& $\mathbf{4 . 3 9} \pm \mathbf{0 . 0 2}$ & $\mathbf{4 . 6 0} \pm \mathbf{0 . 0 2}$ \\
Boric acid & $4.34^{47}$ & \\
& $\mathbf{9 . 1 3} \pm \mathbf{0 . 0 4}$ & $\mathbf{9 . 3 4} \pm \mathbf{0 . 0 4}$ \\
& $8.98^{48}, 9.05^{49}$ &
\end{tabular}

${ }^{a}$ Extrapolation to infinite dilution according to the Davies approach. ${ }^{40}$ (a)

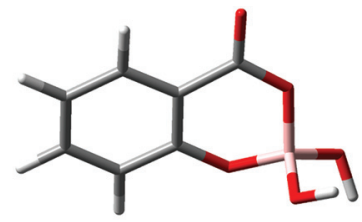

(c)

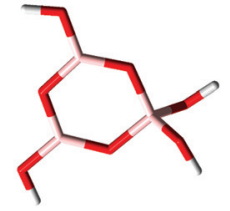

(e)

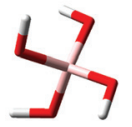

(d)

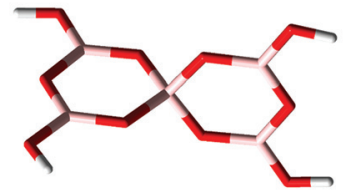

(f)

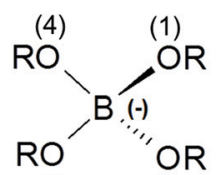

(3)

(2)

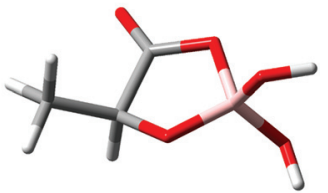

Fig. 4 Optimized structures of (a) salicylatoborate, (b) lactatoborate, (c) triborate $\mathrm{B}_{3} \mathrm{O}_{3}(\mathrm{OH})_{4}{ }^{-}$, (d) pentaborate $\mathrm{B}_{5} \mathrm{O}_{6}(\mathrm{OH})_{4}{ }^{-}$, and (e) monoborate $\mathrm{B}(\mathrm{OH})_{4}{ }^{-}$; pink: boron, red: oxygen, white: hydrogen, grey: carbon; ( $f$ ) general $B(O R)_{4}{ }^{-}$unit $(\mathrm{R}=\mathrm{H}$, other threefold coordinated boron center (s), organic moieties).
The general borate structure $\left(\mathrm{B}(\mathrm{OR})_{4}{ }^{-}\right.$unit) occurring in all the considered borates is shown in Fig. $4 \mathrm{f}$. For the attribution of the structural parameters from DFT calculations (bond lengths, angles) the atoms are numbered in the general $\mathrm{B}(\mathrm{OR})_{4}{ }^{-}$unit (Fig. 4f).

The $\mathrm{B}(\mathrm{OR})_{4}{ }^{-}$units in all calculated borate structures exhibit only slight deviations concerning the determined $\mathrm{B}-\mathrm{O}$ bond lengths and $\mathrm{O}-\mathrm{B}-\mathrm{O}$ angles (Table 3 ). In the BLac structure the $\mathrm{O}(3)-\mathrm{B}-\mathrm{O}(4)$ angle is smaller than in other borate structures due to the formation of a five-membered ring. The structural parameters of BLac are in good agreement with the calculated glycolatoborate structure (five-membered ring) ${ }^{50}{ }^{50}$ Furthermore, in the organoborate structures the $\mathrm{B}-\mathrm{O}(4)$ bond is somewhat longer (on average $\sim 0.07 \AA$ ) than the $\mathrm{B}-\mathrm{O}(1 / 2 / 3)$ bond. This is not the case in the inorganic borate structures. The bond $\mathrm{B}-\mathrm{O}(4)$ is longer in the organoborates, because the electrons of $\mathrm{O}(4)$ are involved in the mesomerism of the ester group. Nevertheless, in all calculated borate structures the structural parameters of the $\mathrm{B}(\mathrm{OR})_{4}{ }^{-}$unit are almost identical, thus, allowing the conclusion that these borate structures should have a comparable complexation behavior to $\mathrm{An} / \mathrm{Ln}(\mathrm{III})$, as expected in our hypothesis (see the Introduction section).

The formation of BSal, BLac and B-3-HB was studied by means of ${ }^{11} \mathrm{~B}$ NMR spectroscopy.

The existence of organoborates can be clearly verified by specific ${ }^{11} \mathrm{~B}$ NMR signals. In the ${ }^{11} \mathrm{~B}$ NMR spectrum of the organic-boron system two characteristic signals were found. A signal at $19.3 \mathrm{ppm}$ appears in every ${ }^{11} \mathrm{~B}$ NMR spectrum. It can be assigned to boric acid. ${ }^{9,51}$ According to DFT calculations at the B3LYP level, the ${ }^{11} \mathrm{~B}$ chemical shift of boric acid appears at $19.8 \mathrm{ppm}$ (relative to $\mathrm{BF}_{3}$ etherate), Table $\mathrm{S} 2, \dagger$ which is in agreement with the NMR experiments. Furthermore ${ }^{11} \mathrm{~B}$ chemical shifts at 2.9, 6.3, and $1.1 \mathrm{ppm}$ for the salicylate-boron, lactate-boron and 3-hydroxybutyrate-boron systems, respectively, were observed (Fig. S6†). The former two chemical shifts are assigned to BSal and BLac, respectively, being in very good agreement with the DFT calculated ${ }^{11} \mathrm{~B}$ chemical shifts of $2.5 \mathrm{ppm}$ and $6.1 \mathrm{ppm}$ (Table S2 $\uparrow$ ). The ${ }^{11} \mathrm{~B}$ chemical shift of $\mathrm{BSal}$ is also in good agreement with the literature. ${ }^{52}$

To evaluate the reliability of the B3LYP functional for the borate system, we additionally tested the TPSSh and PBE0 functionals for several organic and inorganic borate complexes. Structural parameters as well as NMR chemical shifts from these calculations are shown in Table S2. $\dagger$ The deviation of $\mathrm{B}-\mathrm{O}$ bond distances among different theories never exceeds $0.01 \AA$ and the structural agreement is excellent. The accuracy of the ${ }^{11} \mathrm{~B}$ NMR chemical shift using these three different functionals is at a comparable level. For the sake of consistency with our previous studies on Eu complexes, ${ }^{23}$ we decided to use the B3LYP functional in this study.

Difficulties arose in the 3-HB-boron system. DFT calculations at the B3LYP level predicted ${ }^{11} \mathrm{~B}$ chemical shifts for B-3-HB at $2.2 \mathrm{ppm}$ and $2.5 \mathrm{ppm}$ for $\mathrm{L}-$ and D-isomers, respectively (Table S2 $\dagger$ ). However, no chemical shift at $2.2 \mathrm{ppm}$ $( \pm 0.5 \mathrm{ppm})$ was observed in the NMR spectrum, and only an unexpected signal at $1.1 \mathrm{ppm}$ occurred. The DFT calculations 
Table 3 Overview about the structural parameters (bond lengths in $[\AA \AA]$, angles in $\left[^{\circ}\right]$ ) of different optimized organoborates and inorganic (poly)borates; numbering according to Fig. $4 \mathrm{f}$

\begin{tabular}{|c|c|c|c|c|c|c|}
\hline & BSal & BLac & Glycolatoborate $^{b}$ & $\mathrm{~B}(\mathrm{OH})_{4}^{-}$ & $\mathrm{B}_{3} \mathrm{O}_{3}(\mathrm{OH})_{4}{ }^{-}$ & $\mathrm{B}_{5} \mathrm{O}_{6}(\mathrm{OH})_{4}{ }^{-}$ \\
\hline $\mathrm{B}-\mathrm{O}(1)$ & 1.455 & 1.447 & 1.39 & 1.495 & 1.466 & 1.477 \\
\hline $\mathrm{B}-\mathrm{O}(2)$ & 1.443 & 1.462 & & 1.474 & 1.466 & 1.477 \\
\hline $\mathrm{B}-\mathrm{O}(4)$ & $1.520^{a}$ & $1.552^{a}$ & $1.58^{a}$ & 1.482 & 1.497 & 1.477 \\
\hline $\mathrm{O}(1)-\mathrm{B}-\mathrm{O}(2)$ & 115 & 113 & 112 & 113 & 113 & 111 \\
\hline $\mathrm{O}(2)-\mathrm{B}-\mathrm{O}(3)$ & 111 & 115 & & 110 & 106 & 109 \\
\hline
\end{tabular}

for all but this organoborate compound predicted the positions of the NMR signals very precisely. Thus, the missing $2.2 \mathrm{ppm}$ signal means that there is no or only a very weak formation of $\mathrm{B}-3-\mathrm{HB}$ (at least below the detection limit of the NMR spectrometer).

The signal at $1.1 \mathrm{ppm}$ has most likely to be assigned to another borate species. Two possible explanations of this signal exist. A first explanation can be derived from the literature. Miyazaki et al. described a ${ }^{11} \mathrm{~B}$ NMR signal at $1.8 \mathrm{ppm}$ in the ethane-1,2-diol/propane-1,3-diol-borate system assigned to an organoborate ester, where the fourfold coordinated boron center is maintained but no ring structure is formed. ${ }^{53}$ Therefore, the ${ }^{11} \mathrm{~B}$ NMR signal of this non-chelate monodentate organoborate ester is comparable to the free monoborate anion $\left(1.7 \mathrm{ppm}^{54}\right)$. The formation of such an organoborate structure could also be the case in the 3-HB-boron system. The DFT calculated chemical shift of this organoborate species would be $2.1 \mathrm{ppm}$. The second explanation is derived from the experimental conditions. The total boron concentration used in this system was $0.6 \mathrm{M}$ and $0.7 \mathrm{M}$ (at pH 5), i.e., higher than in the other two investigated organic-boron systems. Thus, the signal could be attributed to the pentaborate anion (1.2 ppm). At concentrations above $0.5 \mathrm{M} c_{\mathrm{B} \text {,total }}$ and pH 5 a slight polyborate formation was observed by ${ }^{11} \mathrm{~B}$ NMR spectroscopy in a previous work. ${ }^{9}$ Because of the high signal position similarity the occurrence of pentaborate is the most likely explanation for the discrepancy between the calculated and measured signal position of the supposed B-3-HB. As a result the formation of this species is very weak and is not measureable by NMR.

It seems that the ring size of the formed organoborate has a stronger influence on the ${ }^{11} \mathrm{~B}$ chemical shift than the nature of the organic moiety (e.g., inductive effect) bound to the $\mathrm{B}(\mathrm{OR})_{4}{ }^{-}$ unit. The ${ }^{11} \mathrm{~B}$ chemical shift of BLac $(6.3 \mathrm{ppm})$, possessing a five-membered ring, is remarkably more downfield shifted than that of BSal (2.9 ppm) or B-3-HB (chemical shift not observed, but calculated to be $\sim 2.2 \mathrm{ppm}$ ), where six-membered rings are formed. The ring size effect on the ${ }^{11} \mathrm{~B}$ chemical shift of organoborates and, therefore, the differentiation of fivemembered and six-membered organoborates is also known from the literature. ${ }^{53,55,56}$ The ${ }^{11} \mathrm{~B}$ chemical shifts from our DFT calculations based on the optimized organoborate struc- ture for BLac (6.1 ppm) and BSal (2.5 ppm) support the formation of such rings.

The nature of the organic moiety in the $\mathrm{B}(\mathrm{OR})_{4}{ }^{-}$unit has only a slight influence on the ${ }^{11} \mathrm{~B}$ chemical shift of the organoborate compared to the impact of the ring size. Regardless of the ring size, the carbonyl group typically induces downfield shifts of about 1-2 ppm:

BLac (five-membered ring, carbonyl group): $\delta_{\mathrm{obs}}=6.3 \mathrm{ppm}$, ethane-1,2-diol borate (five-membered ring, no carbonyl group): $\delta_{\text {obs }}=5.6 \mathrm{ppm},{ }^{53}$

BSal (six-membered ring, carbonyl group): $\delta_{\text {obs }}=2.9 \mathrm{ppm}$, propane-1,3-diol borate (six-membered ring, no carbonyl group): $\delta_{\text {obs }}=1.0$ ppm. ${ }^{53}$

Regarding the initial hypothesis, from theoretical calculations and NMR studies of organoborates it can be stated that the Eu(III) complexation with organoborates should be not significantly influenced by the nature of the organic moieties at the $\mathrm{B}(\mathrm{OR})_{4}{ }^{-}$unit. The possible effect of organoborate ring size on the reactivity of the $\mathrm{B}(\mathrm{OR})_{4}{ }^{-}$unit concerning $\mathrm{Eu}(\mathrm{III})$ is not assessable and remains to be seen in the following described complexation studies.

The formation constants $K_{\mathrm{BL}}$, according to eqn (1c), of BSal and BLac were determined from ${ }^{11} \mathrm{~B}$ NMR spectroscopic data. A detailed listing of the $\lg K_{\mathrm{BL}}$ values of the investigated organoborates for different composed solutions is shown in Table S3, $\dagger$ and the average values are summarized in Table 4 . For BSal and BLac the averaged formation constants, $\lg K_{\mathrm{BL}}=1.10 \pm 0.14$ and $0.57 \pm 0.22$, respectively, were obtained. These values are comparable to literature data. ${ }^{42,44,50,52,57-62}$ As discussed above, the formation of $\mathrm{B}-3-\mathrm{HB}$ is not detectable by ${ }^{11} \mathrm{~B}$ NMR spectroscopy. A $K_{\mathrm{BL}}$ for this species cannot be obtained from NMR experiments. No literature data are available for $\lg K_{\mathrm{BL}}$ of B-3-HB.

Taking into account the very weak formation of B-3-HB, it can be stated that the formation constant of the organoborate increases with decreasing $\mathrm{p} K_{\mathrm{a}}$ of its corresponding organic acid.

It is noteworthy that the reaction according to eqn (1c) is isocoulombic, i.e., the extrapolation to infinite dilution by following the Davies approach ${ }^{40}$ does not change the value of $\lg K_{\mathrm{BL}}$ determined at $I=0.1 \mathrm{M}$.

An example for a speciation calculation for the investigated organic-boron systems is shown in Fig. 5 (calculated using 
Table 4 Organoborate formation constants $K_{\mathrm{BL}}$ (according to eqn (1c)) and Eu(III) complexation constants $\beta_{\text {EuL }}$ and $\beta_{\text {EuL }}$ (according to eqn (1d) and (e)) determined in this work (bold text) in comparison with the literature; $T=22-25^{\circ} \mathrm{C}$; deviation: $2 \sigma$

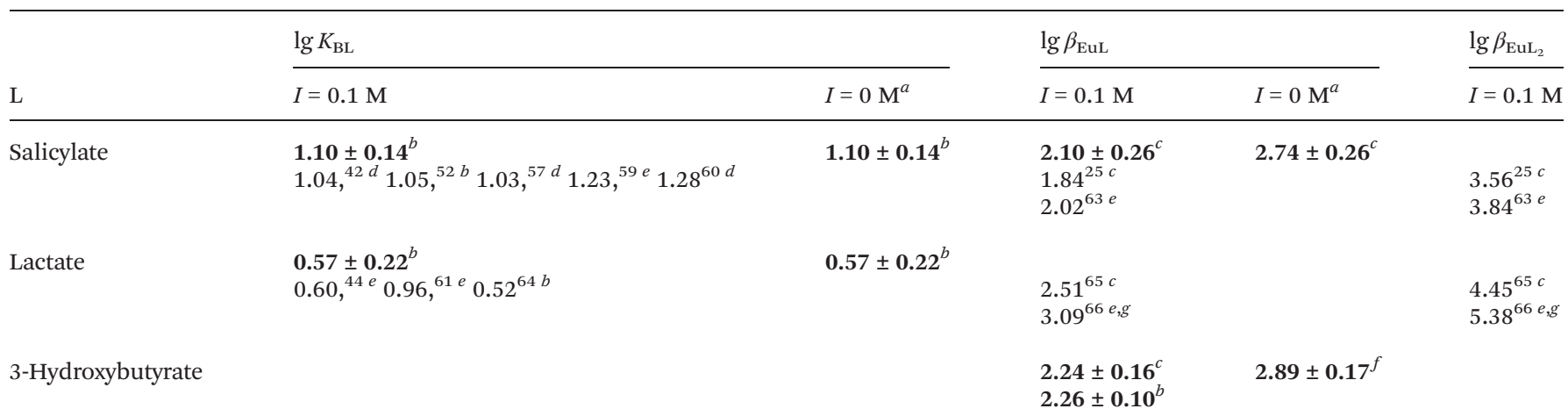
${ }^{a}$ Extrapolation to infinite dilution according to the Davies approach. ${ }^{40}{ }^{b}$ NMR spectroscopy. ${ }^{c}$ TRLFS. ${ }^{d}$ Photometry. ${ }^{e}$ Potentiometry. ${ }^{f}$ Average of
both methods. ${ }^{g}$ Dy(III) instead of Eu(III).

HySS $^{28}$ ). In all systems the amount of the respective organoborate reaches its maximum at $\mathrm{pH} 5-6$. At $\mathrm{pH}>8$ the content of organoborate distinctly decreases, because the concentration of available boric acid decreases (eqn (1b)). Thus, the optimum $\mathrm{pH}$ for the existence of organoborates is in the range $\mathrm{p} K_{\mathrm{a}}\left(\right.$ organic acid) $<\mathrm{pH}<\mathrm{p} K_{\mathrm{a}}($ boric acid) (also found by Van Duin et $\left.a l .{ }^{67}\right)$.

The very weak formation of B-3-HB made valid complexation experiments with $\mathrm{Eu}(\mathrm{III})$ impossible. Nevertheless, a $\mathrm{Eu}-3-\mathrm{HB}$ complex $\left(\beta_{\mathrm{Eu}(3-\mathrm{HB})}\right)$ was determined from TRLFS and ${ }^{1} \mathrm{H}$ NMR spectroscopic investigations (see the next subsection).

Eu(III) complexation with 3-hydroxybutyrate (3-HB), salicylate (Sal) and lactate (Lac)

The Eu-3-HB complexation constant $\beta_{\mathrm{Eu}(3-\mathrm{HB})}($ Table 4) was determined from TRLFS and ${ }^{1} \mathrm{H}$ NMR spectroscopic data (Fig. S4, S5, and Table S1 $\dagger$ ) processed as described in the section "Data analysis". Both spectroscopic methods delivered very similar complexation constants, yielding an average $\lg \beta_{\mathrm{Eu}(3-\mathrm{HB})}=2.25 \pm 0.17\left(\lg \beta_{\mathrm{Eu}(3-\mathrm{HB})}^{0}=2.89 \pm 0.17\right)$. This value is comparable to the complexation constant for the Pr-3-HB complex $\left(\lg \beta_{\mathrm{Pr}(3-\mathrm{HB})}=2.08^{47}\right.$ (potentiometry), the only comparable system found in the literature).

The complexation constant $\beta_{\text {EuSal }}$ (Table 4) was determined from TRLFS data. The analysis yielded an average $\lg \beta_{\text {EuSal }}=$ $2.10 \pm 0.26\left(\lg \beta_{\text {Eusal }}^{0}=2.74 \pm 0.26\right)$. This value, together with the obtained (pure) stationary luminescence spectrum of the $1: 1 \mathrm{Eu}-\mathrm{Sal}$ complex was used to derive the complexation constant $\beta_{\mathrm{Eu}(\mathrm{BSal})}$ from TRLFS data (see below).

Table 4 summarizes $\lg \beta_{\mathrm{EuL}}$ for $\mathrm{L}=\mathrm{Sal} / \mathrm{Lac} / 3-\mathrm{HB}$ and $\lg \beta_{\mathrm{EuL}_{2}}$ for $\mathrm{L}=\mathrm{Sal} / \mathrm{Lac}$ both from this work and the literature. These $\mathrm{Eu}(\mathrm{III})$-organic complexation constants are involved in the

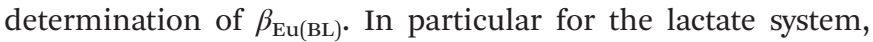
the $1: 2 \mathrm{Eu}(\mathrm{III})$ complex is required.
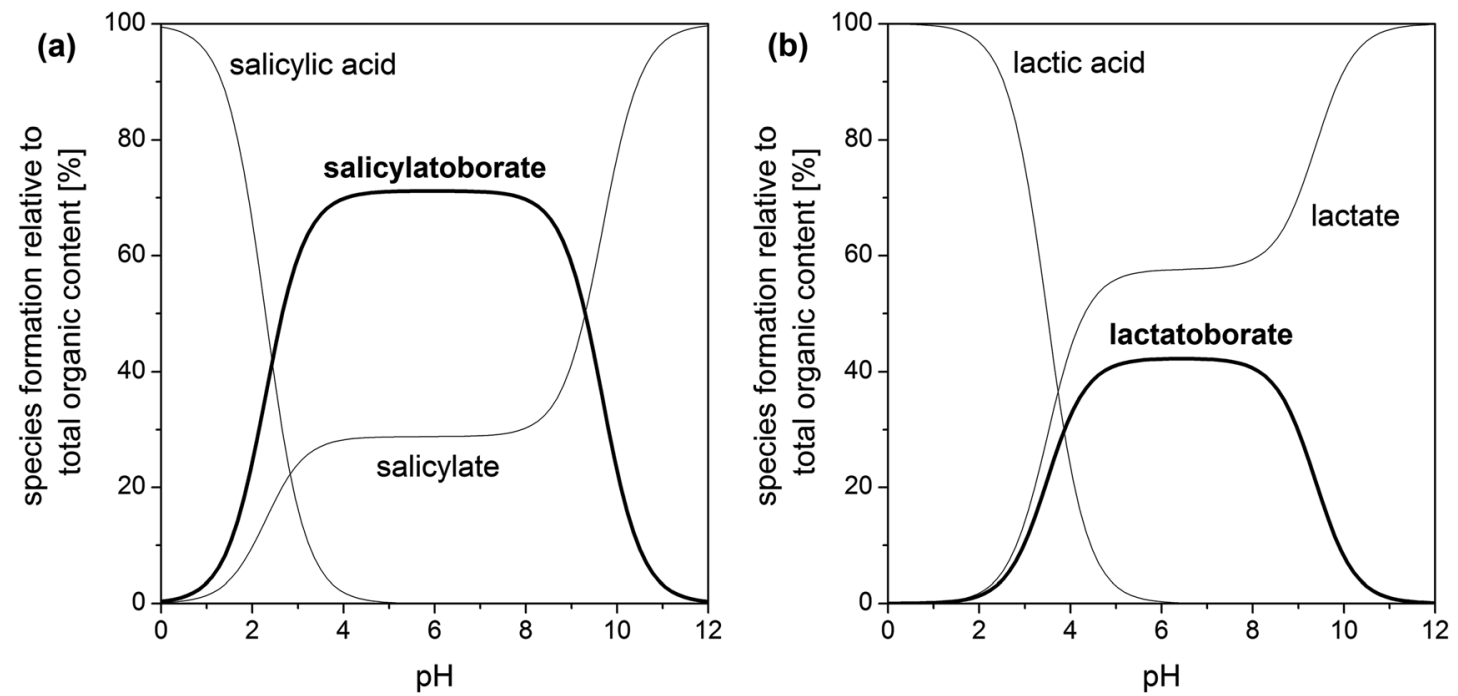

Fig. 5 Speciation of different organic-boron systems for solutions with $5 \mathrm{mM}$ total organic and $200 \mathrm{mM}$ total boron concentration, $I=0.1 \mathrm{M}, T=$ $22^{\circ} \mathrm{C}$ (our data for $\mathrm{p} K_{\mathrm{a}}$ and $K_{\mathrm{BL}}$ taken from Tables 2 and 4): (a) salicylate-boron system and (b) lactate-boron system. 
Obviously, the $\beta_{\text {EuLac }}$ and $\beta_{\text {EuLac }}$ determined by different experimental methods deviate significantly from each other. ${ }^{68}$ Therefore, the upper and lower limits for $\beta_{\mathrm{EuLac}}$ and $\beta_{\mathrm{EuLac}_{2}}$ were used to determine the upper and lower limits of $\beta_{\mathrm{Eu}(\mathrm{BLac})}$.

\section{Eu(III)-organoborate complexation studies}

The complexation of Eu(III) with BSal and BLac was studied by means of TRLFS and ${ }^{11} \mathrm{~B}$ NMR spectroscopy as well as by DFT calculations.

At first the results of TRLFS studies are presented.

The presence of boric acid as the boron source influences the $\mathrm{Eu}(\mathrm{III})$-organic speciation. This can be shown by comparing the europium luminescence spectra (Fig. 6). The spectra for the $\mathrm{Eu}$ (III)-salicylate (Fig. 6, Ia) and Eu(III)-lactate systems (Fig. 6, Ib) clearly differ from the spectra in the presence of boric acid under the same conditions (Fig. 6, IIa and IIb, respectively). There are two explanations for the observed intensity decrease of the ${ }^{5} \mathrm{D}_{0} \rightarrow{ }^{7} \mathrm{~F}_{0}$ transition at $\sim 578 \mathrm{~nm}$ and ${ }^{5} \mathrm{D}_{0} \rightarrow{ }^{7} \mathrm{~F}_{2}$ transition at $\sim 616 \mathrm{~nm}$ : (1) removal of free salicylate/ lactate (complexing the europium) due to the formation of the respective organoborate, and, (2) different luminescence properties of the $\mathrm{Eu}(\mathrm{III})$-organoborate complex in comparison with the $\mathrm{Eu}(\mathrm{III})$-salicylate/lactate complexes.

The time-resolved luminescence spectra of a series of solutions containing varying concentrations of total boron and constant concentrations of $\mathrm{Eu}(\mathrm{III})\left(3 \times 10^{-5} \mathrm{M}\right)$ and of the organic compound $(10 \mathrm{mM})$ were analyzed by PARAFAC. This provided the $\mathrm{Eu}(\mathrm{III})$ speciation for the respective system as shown in Fig. 7. In the Eu(III)-salicylate-boron system as well as in the $\mathrm{Eu}$ (III)-lactate-boron system the amount of the $\mathrm{Eu}(\mathrm{III})$-organoborate complex increases with increasing total boron concentration due to the increasing formation of the respective organoborate. Parallel to that a decrease in the formation of the $\mathrm{Eu}(\mathrm{III})$-organic complex(es) can be observed.
This is explainable with the decrease of free available organic content for the $\mathrm{Eu}(\mathrm{III})$ complexation due to the increasing formation of the organoborate.

From PARAFAC the luminescence lifetimes of Eu(III) species were extracted (summarized in Fig. 7). The luminescence lifetimes for the Eu-BSal complex and Eu-BLac complex were determined to be $319 \mu \mathrm{s}$ and $132 \mu \mathrm{s}$, respectively. The luminescence lifetime of the Eu-BLac is comparable to that of the $\mathrm{Eu}(\mathrm{III})$-polyborate complex exhibiting a lifetime of $\sim 150 \mu \mathrm{s}^{9}{ }^{9}$ This is a first support of our hypothesis that borates with the general $\mathrm{B}(\mathrm{OR})_{4}{ }^{-}$unit show a comparable complexation behavior concerning trivalent lanthanides (and actinides). The luminescence lifetime of the Eu-BSal complex calculated with PARAFAC is strongly increased in comparison with the EuBLac and -polyborate complex. However, we expect a similar $\mathrm{Eu}(\mathrm{III})$ complexation with BSal as with the other described borate ligands (see the hypothesis).

The BSal system was the most suitable system to study the Eu(III) complexation at a low metal concentration $\left(3 \times 10^{-5} \mathrm{M}\right)$ by TRLFS, because of the high formation yield of BSal and the well characterized $\mathrm{Eu}(\mathrm{III})$-salicylate complexation as the secondary reaction system. Unfortunately, the Eu-BLac TRLFS titration series were very difficult to analyse. Due to the stronger $\mathrm{Eu}(\mathrm{III})$-lactate complexation and more pronounced formation of the $1: 2$ complex already at low lactate concentrations (in comparison with the salicylate system; see $\mathrm{Eu}(\mathrm{III})$ organic speciations in Fig. S7 $\dagger$ ) a separation of the $\mathrm{Eu}-$ BLac complex from the stationary TRLFS titration data was not possible. Only the analysis of the $\mathrm{Eu}(\mathrm{III})$ speciation in the Eu(III)-lactate-boron system (Fig. 7b) determined by PARAFAC of the time-resolved spectra gave a hint of the Eu-BLac complexation (see below).

The Eu-BSal complexation constant was determined from TRLFS pH titration series of solutions containing Eu(III) and
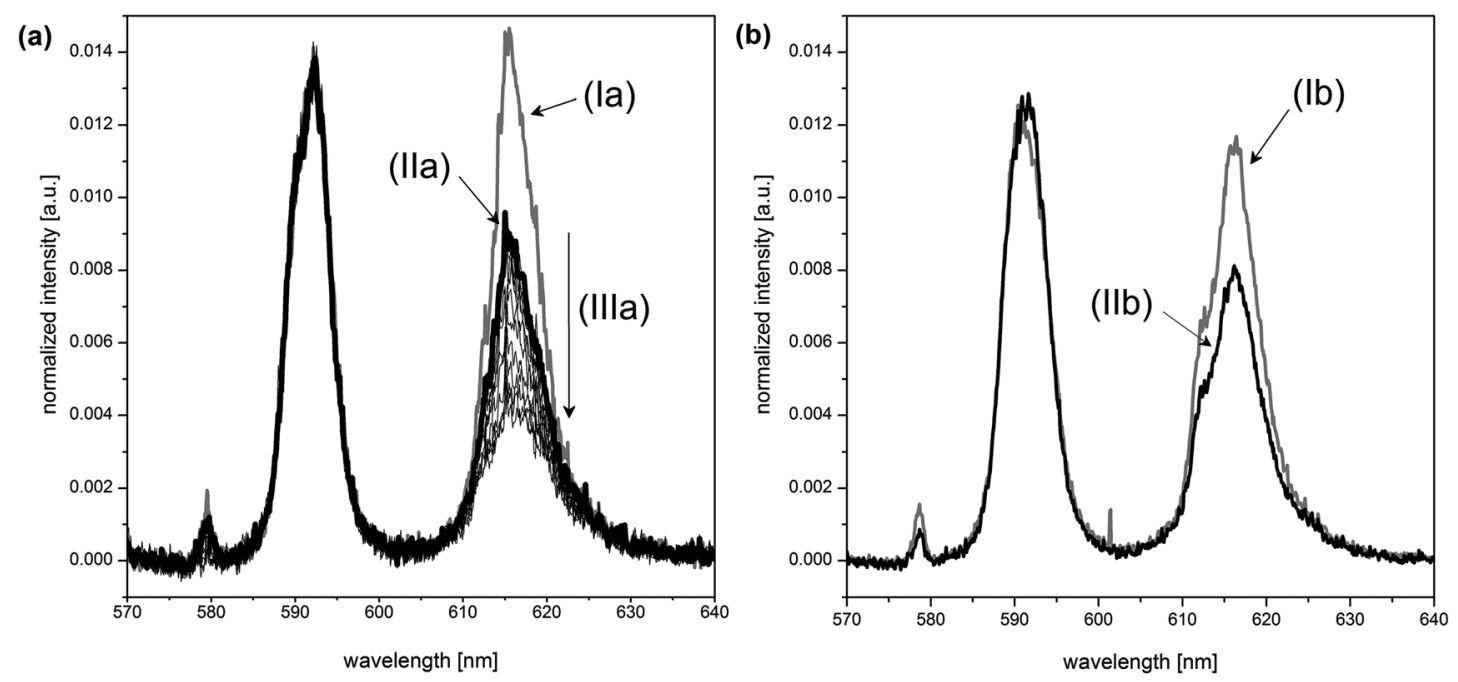

Fig. 6 Influence of boric acid on the spectra in the (a) Eu(III)-salicylate and (b) Eu(III)-lactate system at pH $\sim 4.4$ and $3 \times 10^{-5} \mathrm{M} \mathrm{Eu(III).} \mathrm{Eu} \mathrm{lumine-}$ scence spectra in the presence of (la) $10 \mathrm{mM}$ salicylate, (Ila) $10 \mathrm{mM}$ salicylate and $200 \mathrm{mM}$ total boron, (Ib) $2 \mathrm{mM}$ lactate, (Illb) $2 \mathrm{mM}$ lactate and $400 \mathrm{mM}$ total boron, (IIla) $\mathrm{pH}$ titration of a solution containing $3 \times 10^{-5} \mathrm{M} \mathrm{Eu(III),} 10 \mathrm{mM}$ salicylate and $200 \mathrm{mM}$ total boron down to $\mathrm{pH} \sim 2$. 

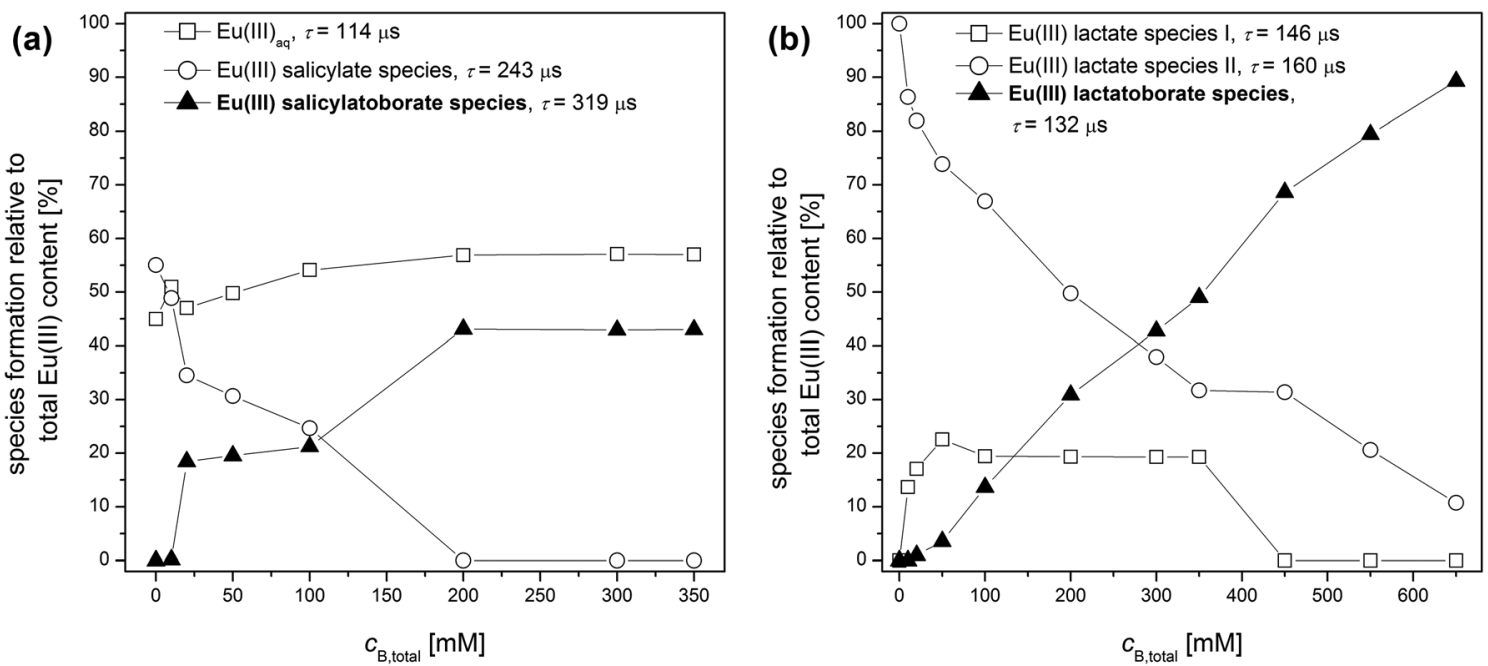

Fig. 7 Europium(III) speciation in solutions containing $3 \times 10^{-5} \mathrm{M} \mathrm{Eu(III),10} \mathrm{mM} \mathrm{total} \mathrm{organic} \mathrm{and} \mathrm{varying} \mathrm{total} \mathrm{boron} \mathrm{concentration} \mathrm{at} \mathrm{pH} \mathrm{5,}$ (a) Eu(III)-salicylate-boron system and (b) Eu(III)-lactate-boron system.

varying total concentrations of both salicylate and boron (e.g., Fig. 6, IIIa). In Table 5 the resulting $\lg \beta_{\mathrm{Eu}(\mathrm{BSal})}$ (average) according to eqn (1f) is shown. Several values of $\lg \beta_{\mathrm{Eu}(\mathrm{BSal})}$ are shown

Table $5 \mathrm{Eu}(\mathrm{III})$-organoborate complexation constants $\beta_{\mathrm{Eu}(\mathrm{BL})}$ (according to eqn (1f)) determined within this work; $T=22{ }^{\circ} \mathrm{C}$; deviation: $2 \sigma$; see the last column for used method and parameters for data analysis

\section{$\lg \beta_{\mathrm{Eu}(\mathrm{BL})}$ \\ $I=0.1 \mathrm{M}$ \\ $I=0 \mathrm{M}^{a}$ \\ Method and parameters for data analysis}

Eu(III)-salicylatoborate

$1.93 \pm 0.48 \quad 2.57 \pm 0.48$

$\begin{array}{ll}1.95 \pm 0.32 & 2.59 \pm 0.32\end{array}$

$2.12 \pm 0.28 \quad 2.76 \pm 0.28$

$2.11 \pm 0.32 \quad 2.75 \pm 0.32$

Eu(III)-lactatoborate

$1.94 \pm 0.22$ to $2.58 \pm 0.22$ to

$2.18 \pm 0.26 \quad 2.82 \pm 0.26$

$2.37 \pm 0.26$ to $\quad 3.01 \pm 0.26$ to

$2.61 \pm 0.15 \quad 3.25 \pm 0.15$

$2.68 \pm 0.92 \quad 3.32 \pm 0.92$

\section{TRLFS $^{b}$}

${ }^{11} \mathrm{~B}$ NMR (5 mM salicylate, $200 \mathrm{mM}$ total boron), $\delta_{\text {free }}=2.9 \mathrm{ppm}, \delta_{\text {complex }}^{*}=$ $9.4 \mathrm{ppm}^{b}$

${ }^{11}$ B NMR (10 mM salicylate, $200 \mathrm{mM}$ total boron), $\delta_{\text {free }}=2.9 \mathrm{ppm}, \delta_{\text {complex }}^{*}=$ $9.2 \mathrm{ppm}^{b}$

PARAFAC (10 mM salicylate, varying total boron $)^{b}$

${ }^{11} \mathrm{~B}$ NMR (5 mM lactate, $200 \mathrm{mM}$ boron) $\delta_{\text {free }}=6.3 \mathrm{ppm}, \delta_{\text {complex }}^{*}=21.5$ (lower limit) to $31.2 \mathrm{ppm}$ (upper limit) $^{c}$

${ }^{11} \mathrm{~B}$ NMR (5 mM lactate, $200 \mathrm{mM}$ boron) $\delta_{\text {free }}=6.3 \mathrm{ppm}, \delta_{\text {complex }}^{*}=21.5$ (lower limit) to $31.2 \mathrm{ppm}$ (upper limit) $^{d}$ PARAFAC $(10 \mathrm{mM}$ lactate, varying total boron $)^{c}$

${ }^{a}$ Extrapolation to infinite dilution according to the Davies approach. ${ }^{40}$

${ }^{b}$ Fixed parameters for data analysis: $\mathrm{p} K_{\mathrm{a}, \mathrm{Sal}}=2.83, \lg K_{\mathrm{BSal}}=1.10$, $\lg \beta_{\text {EuSal }}=2.10 .{ }^{c}$ Fixed parameters for data analysis: $\mathrm{p} K_{\mathrm{a}, \mathrm{Lac}}=3.73$, $\lg K_{\text {BLac }}=0.57, \lg \beta_{\text {EuLac }}=2.51^{65}, \lg \beta_{\text {EuLac }_{2}}=4.45 .{ }^{65}{ }^{d}$ Fixed parameters for data analysis: $\mathrm{p} K_{\mathrm{a}, \mathrm{Lac}}=3.73, \lg K_{\mathrm{BLac}}=0.57, \lg \beta_{\text {DyLac }}=3.09^{66}$, $\lg \beta_{\text {DyLac } 2}=5.38 .^{66}$ in Table S4. $\dagger$ For the Eu-BSal complex an average of $\lg \beta_{\mathrm{Eu}(\mathrm{BSal})}$ $=1.93 \pm 0.48$ was determined.

A complexation constant $\lg \beta_{\text {Eu(BSal) }}=2.11 \pm 0.32$ was deduced (Table 5) from PARAFAC of time-resolved luminescence spectra and analysis of the obtained Eu(III) speciation (Fig. 7a). For the Eu(III)-lactate-boron system a complexation constant with a high uncertainty $\left(\lg \beta_{\mathrm{Eu}(\mathrm{BLac})}=2.68 \pm 0.92\right.$, Table 5) was determined similarly. However, the Eu(III) complexation with BLac seems to be somewhat stronger (around half order of magnitude) than that with BSal.

In the following section the results of ${ }^{11} \mathrm{~B}$ NMR spectroscopic studies are presented and discussed.

It has already been shown above (in the section $\mathrm{Eu}$ (III) complexation with 3-hydroxybutyrate (3-HB), salicylate (Sal) and lactate (Lac)) that complexation constants can be derived from NMR spectroscopic data. The Eu(III) induced ${ }^{11} \mathrm{~B}$ NMR signal shift of the organoborates (Fig. S2, S3, and Table S5 $†$ ) was used to determine the complexation constants $\beta_{\mathrm{Eu}(\mathrm{BSal})}$ and $\beta_{\mathrm{Eu}(\mathrm{BLac})}$ according to eqn (1f). The procedure is described in the "Experimental section". The resulting $\lg \beta_{\mathrm{Eu}(\mathrm{BL})}$ (averages) are summarized in Table 5 .

The complexation constant for the Eu-BSal complex from TRLFS and ${ }^{11} \mathrm{~B}$ NMR spectroscopic data agree very well (Table 5) and $\beta_{\mathrm{Eu}(\mathrm{BSal})}$ can be reproduced by both methods. Eventually, this gave $\lg \beta_{\mathrm{Eu} \text { (BSal) }}=2.05 \pm 0.17$ (averaged over all $\lg \beta_{\mathrm{Eu}(\mathrm{BSal})}$ values (TRLFS, NMR and PARAFAC) of Table 5). Extrapolation to infinite dilution yielded $\lg \beta_{\mathrm{Eu}(\mathrm{BSal})}^{0}=2.69 \pm$ 0.17 .

Unfortunately, the literature values of both $\lg \beta_{\text {EuLac }}$ and $\lg \beta_{\text {EuLac }_{2}}$ differ considerably (see Table 4). Furthermore, the uncertainty of $\delta_{\text {complex }}^{*}$ of BLac is much higher than that of BSal (see Table 1). This large uncertainty stems from the overlapping of the ${ }^{11} \mathrm{~B}$ NMR signals of BLac and $\mathrm{B}(\mathrm{OH})_{3}$ with increasing $\mathrm{Eu}(\mathrm{III})$ concentration (Fig. S2b†). Even our attempt to replace $\mathrm{Eu}(\mathrm{III})$ by $\operatorname{Pr}(\mathrm{III})$ or $\mathrm{Dy}(\mathrm{III})$ did not succeed. The 
expected upfield shift of the organoborate ${ }^{11} \mathrm{~B}$ NMR signal as in the case of ${ }^{1} \mathrm{H}$ NMR signals ${ }^{16}$ did not occur. The separation of BLac and $\mathrm{B}(\mathrm{OH})_{3}{ }^{11} \mathrm{~B}$ chemical shifts is possible only up to $15 \mathrm{mM} \mathrm{Eu(III)}$, see Fig. S2b. $\uparrow$ Here, only around one half of BLac binds to the Eu(III). Therefore, a higher uncertainty in the asymptotic fit to determine $\delta_{\text {complex }}^{*}$ is unavoidable.

In the frame of both these uncertainties (deviation in literature data for $\beta_{\text {EuLac }}$ and $\beta_{\mathrm{EuLac}_{2}}$, upper and lower limits of $\delta_{\text {complex }}^{*}$ a more extended data analysis was carried out to determine $\beta_{\mathrm{Eu}(\mathrm{BLac})}$. All possible variations of the upper and lower limits of the input data $\beta_{\text {EuLac }}, \beta_{\text {EuLac }_{2}}$, and $\delta_{\text {complex }}^{*}$ of BLac were used (Tables 5 , and $\mathrm{S} 6 \dagger$ ) to calculate the upper and lower limits of $\beta_{\mathrm{Eu}(\mathrm{BLac}) \text {. }}$

Assuming that the lower limits of the $\mathrm{Eu}(\mathrm{III})$-lactate complex constants are valid $\left(\lg \beta_{\text {EuLac }}=2.51\right.$ and $\lg \beta_{\mathrm{EuLac}_{2}}=$ $4.45)^{65}$ we obtained the following range of the complexation constant for the Eu-BLac complex: $\lg \beta_{\mathrm{Eu}(\mathrm{BLac})}=1.94 \pm 0.22$ to $2.18 \pm 0.26$. If, in contrast, the upper limits of the Eu(III)lactate complex constants are taken to be $\left(\lg \beta_{\text {DyLac }}=3.09\right.$ and $\lg \beta_{\text {DyLac }_{2}}=5.38$; Dy(III) as an Eu(III) analog) ${ }^{66} \lg \beta_{\text {Eu(BLac) }}$ ranges from $2.37 \pm 0.26$ to $2.61 \pm 0.15$. These results are summarized in Table 5. Extrapolation to infinite dilution for the lower limit of $\lg \beta_{\mathrm{Eu}(\mathrm{BLac})}$ yielded $\lg \beta_{\mathrm{Eu}(\mathrm{BLac})}^{0}=2.58 \pm 0.22$ to $2.82 \pm 0.26$ and for the upper limit of $\lg \beta_{\mathrm{Eu}(\mathrm{BLac})} \lg \beta_{\mathrm{Eu}(\mathrm{BLac})}^{0}=3.01 \pm 0.26$ to $3.25 \pm 0.15$.

Taking into account the uncertainties, the complexation constants of both $\mathrm{BSal}$ and $\mathrm{BLac}$ are in the range $\lg \beta_{\mathrm{Eu}(\mathrm{BL})}$ 2.0-2.6 $\left(\lg \beta_{\mathrm{Eu}(\mathrm{BL})}^{0} 2.6-3.2\right)$ and, hence, are comparable and quite weak. The differences result from the high complexity of the equilibrium systems combined with the uncertainties of all involved constants. Though differences in the ${ }^{11} \mathrm{~B}$ NMR signals of both organoborate ligands indicate differences in the electronic structure of the boron atom, both the ring size of the organoborate and the electronic nature of the organic moieties bound to the $\mathrm{B}(\mathrm{OR})_{4}{ }^{-}$unit seems to have only a small influence on $\lg \beta_{\mathrm{Eu}(\mathrm{BL})}$.

Furthermore, the complexation constants of the Eu(III)organoborate complexes are well comparable to the complexation constant $\left(\lg \beta_{11}^{0}=2.66 \pm 0.16\right)^{9}$ of $\mathrm{Eu}(\mathrm{III})$-polyborates (i.e., tri- and pentaborate) with one binding site. This is an important corroboration of the initial hypothesis that borates with the general structural unit $\mathrm{B}(\mathrm{OR})_{4}{ }^{-}{ }^{-}$regardless if $\mathrm{R}$ is organic or inorganic - show a comparable complexation behavior concerning trivalent lanthanides (and actinides).

Finally, the structures of the Eu-BSal and Eu-BLac complex were calculated by DFT. For the sake of comparison and to test the hypothesis that all borate structures show a comparable complexation behavior concerning An/Ln(III), Eu(III) inorganic borate structures were also studied. In order to understand the general tendency of possible binding/coordination modes between $\mathrm{Eu}(\mathrm{III})$ and borates (inorganic as well as organic) an example is shown in Fig. 8, presenting the most likely Eu(III)pentaborate complexes (structures and relative Gibbs energies).

Three different binding modes were calculated for the Eu(III)-pentaborate complex including one monodentate coordination mode $(-\mathrm{B}-\mathrm{O}(\mathrm{H})-\mathrm{Eu})$ where a threefold coordinated boron atom is involved (Fig. 8a), and two complexes with a chelate coordination mode (Fig. $8 \mathrm{~b}$ and c). In one of these chelate complexes a threefold and fourfold coordinated boron unit is involved ( $\mathrm{Eu}-\mathrm{O}(\mathrm{H})-\mathrm{B}-\mathrm{O}-(\mathrm{Eu}))$, Fig. $8 \mathrm{~b}$, and in the other chelate the fourfold coordinated boron unit of the pentaborate is involved (Eu-O-B-O-(Eu)), Fig. 8c. The calculated relative Gibbs energies of these complexes are very similar. The energy difference between the most and least stable structures is only $12 \mathrm{~kJ} \mathrm{~mol}^{-1}$. From this, one cannot decide,

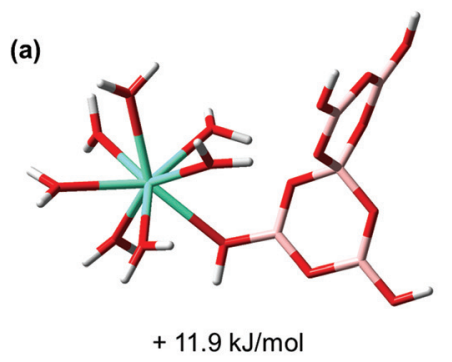

(b)

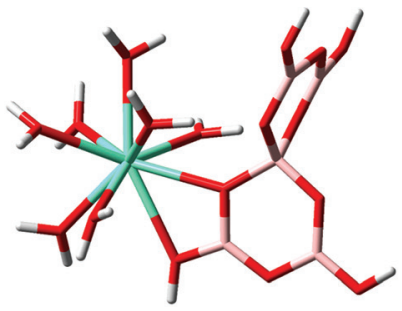

(c)

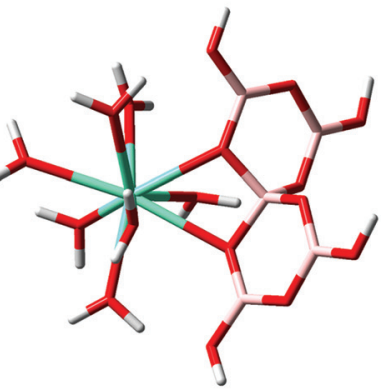

$+8.4 \mathrm{~kJ} / \mathrm{mol}$

$\pm 0.0 \mathrm{~kJ} / \mathrm{mol}$

Fig. 8 Possible Eu(III) coordination modes in the Eu(III) pentaborate complex. (a) Monodentate Eu(III) coordination, (b) chelate Eu(III) coordination via threefold and fourfold coordinated boron units, (c) chelate Eu(III) coordination via a fourfold coordinated boron unit; cyan: europium, pink: boron, red: oxygen, white: hydrogen. 
whether there is a preferred structure in reality. However, we know from TRLFS studies that an interaction between Eu(III) and boron compounds with a threefold coordinated boron unit, e.g., boric acid, does not occur. This is a hint regarding the preference of the chelate of the $\mathrm{Eu}(\mathrm{III})$-pentaborate complex shown in Fig. 8c. Moreover, in the crystal structures of $\mathrm{Ln}(\mathrm{III})$ - and An(III)-polyborates, reported in the literature, ${ }^{69,70} 4$-membered chelate rings are found, supporting the chelate motif as shown in Fig. 8c rather than as in Fig. 8b.

In the case of Eu-BSal, Eu-BLac, Eu(III)-monoborate, and Eu(III)-triborate complexes, chelate and monodentate Eu(III) coordination modes by the fourfold coordinated boron unit were calculated as well. Both coordination modes are also energetically very similar and, thus, not distinguishable. However, in analogy with $\mathrm{Eu}(\mathrm{III})$ coordination to pentaborate, the chelate $\mathrm{Eu}(\mathrm{III})$ coordination in these complexes is more likely. It is also conceivable that the monodentate and chelate complexes are in equilibrium. (a)

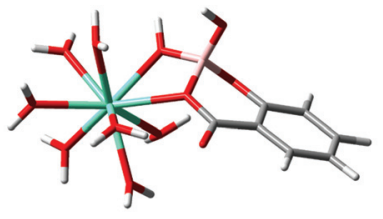

(c)

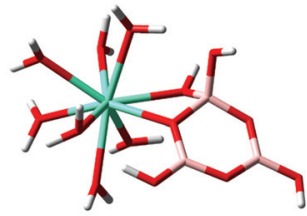

(e)

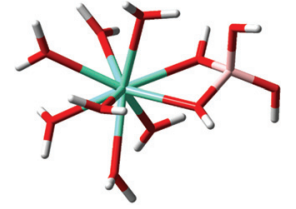

(b)

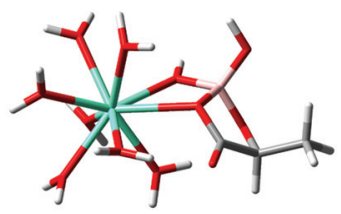

(d)

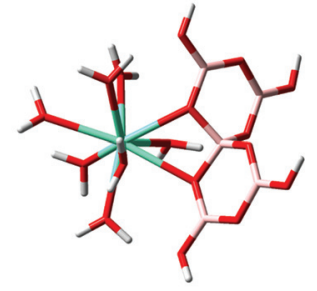

(f)
Fig. 9 Calculated chelate Eu(II) complexes of (a) salicylatoborate, (b) lactatoborate, (c) triborate $\mathrm{B}_{3} \mathrm{O}_{3}(\mathrm{OH})_{4}{ }^{-}$, (d) pentaborate $\mathrm{B}_{5} \mathrm{O}_{6}(\mathrm{OH})_{4}^{-}$and (e) monoborate $\mathrm{B}(\mathrm{OH})_{4}{ }^{-}$; cyan: europium, pink: boron, red: oxygen, white: hydrogen, grey: carbon; (f) general $\mathrm{Eu}\left(\mathrm{B}(\mathrm{OR})_{4}\right)^{2+}$ complex $(\mathrm{R}=\mathrm{H}$, other threefold coordinated boron center(s), organic moieties).
As a summary of the DFT section the structures (in chelate coordination mode, assuming coordination number 9) of EuBSal, Eu-BLac, Eu(III)--monoborate, Eu(III)-triborate and Eu(III)-pentaborate optimized at the B3LYP level are presented in Fig. 9.

The structural parameters of the optimized organic and inorganic Eu(III)-borate complexes are shown in Fig. S8-S12, and Tables S7-S11. $\dagger$

For comparison the structural parameters of the Eu(III)$\mathrm{B}(\mathrm{OR})_{4}{ }^{-}$unit in the complexes are summarized in Table 6 (referring to Fig. 9f). It turns out that the structural parameters of the considered Eu(III)-borate complexes (Table 6) are comparable. The $\mathrm{Eu}-\mathrm{O}(1)$ and $\mathrm{Eu}-\mathrm{B}$ distances in the considered Eu(III)-borate complexes, Table 6, have a maximum deviation of $0.1 \AA$. The deviation in the $\mathrm{Eu}-\mathrm{O}(4)$ bond distance is somewhat higher (maximum $0.2 \AA$ ). Because the difference in the $\mathrm{Eu}-\mathrm{O}(4)$ bond lengths is independent of the nature of the borate ligand (organic or inorganic) this higher deviation in the case of the $\mathrm{Eu}-\mathrm{O}(4)$ bonding could be a consequence of the steric flexibility of the borate structures (BLac and pentaborate might be less flexible than the other borate structures). The bond angles in the $\operatorname{EuB}(\mathrm{OR})_{4}{ }^{2+}$ complex are also comparable. In particular the (B-)O-Eu-O (-B) bond angle only deviates within $1.1^{\circ}$. Due to the $\mathrm{Eu}(\mathrm{III})$ binding the $\mathrm{O}(1)-\mathrm{B}-\mathrm{O}(4)$ angles become smaller in comparison with the free borate structures (comparing $\mathrm{O}(1)-\mathrm{B}-\mathrm{O}(4)$ in Tables 3 and 6).

The listed structural similarities indicate the comparable bonding of $\mathrm{Eu}(\mathrm{III})$ to the $\mathrm{B}(\mathrm{OR})_{4}{ }^{-}$unit in the considered borates. This supports the experimental data (TRLFS, ${ }^{11} \mathrm{~B}$ NMR) of all investigated inorganic (poly)borates as well as different organoborates in which the same order of magnitude $\left(\lg \beta^{0}=2.6-3.2\right)$ for the complexation was determined. The observed differences in a few structural parameters (due to the ring size of the organoborates, moieties at the $\mathrm{B}(\mathrm{OR})_{4}{ }^{-}$unit or flexibility of borate molecules) have only a small effect on the $\mathrm{Eu}(\mathrm{III})-\mathrm{B}(\mathrm{OR})_{4}{ }^{-}$ complexation. The complexation in the $\mathrm{Eu}(\mathrm{III})-\mathrm{B}(\mathrm{OR})_{4}{ }^{-}$system is comparable within the obtained uncertainty limits.

\section{Conclusion}

This work was started with the hypothesis that borate structures with one general $\mathrm{B}(\mathrm{OR})_{4}{ }^{-}$unit show comparable com-

Table 6 Overview about the structural parameters (bond lengths in $[\AA ̊]$, angles in [ $\left.{ }^{\circ}\right]$ ) of different optimized Eu(III) organoborates and Eu(III) inorganic (poly)borates; numbering according to Fig. $9 f$

\begin{tabular}{|c|c|c|c|c|c|}
\hline & Eu-BSal & $\mathrm{Eu}-\mathrm{BLac}$ & $\mathrm{Eu}\left(\mathrm{B}(\mathrm{OH})_{4}\right)^{2+}$ & $\mathrm{Eu}\left(\mathrm{B}_{3} \mathrm{O}_{3}(\mathrm{OH})_{4}\right)^{2+}$ & $\mathrm{Eu}\left(\mathrm{B}_{5} \mathrm{O}_{6}(\mathrm{OH})_{4}\right)^{2+}$ \\
\hline $\mathrm{Eu}-\mathrm{O}(1)$ & 2.438 & 2.405 & 2.392 & 2.448 & 2.498 \\
\hline $\mathrm{Eu}-\mathrm{O}(4)$ & 2.536 & 2.698 & 2.465 & 2.533 & 2.641 \\
\hline $\mathrm{O}(1)-\mathrm{B}-\mathrm{O}(4)$ & 98.4 & 98.8 & 96.0 & 99.2 & 103.2 \\
\hline $\mathrm{O}(3)-\mathrm{B}-\mathrm{O}(4)$ & 106.0 & 100.4 & 117.1 & 111.6 & 112.7 \\
\hline $\mathrm{Eu}-\mathrm{O}(1)-\mathrm{B}$ & 106.6 & 111.2 & 103.3 & 102.6 & 103.0 \\
\hline
\end{tabular}


plexation behavior concerning trivalent lanthanides and actinides. This hypothesis was confirmed both by experimental $\mathrm{Eu}(\mathrm{III})$-borate complexation studies using the complementary methods TRLFS and ${ }^{11} \mathrm{~B}$ NMR, and theoretical DFT calculations. Borates (organic or inorganic) with the structural unit $\mathrm{B}(\mathrm{OR})_{4}{ }^{-}$show a weak complexation with $\mathrm{Eu}(\mathrm{III})$ as a $1: 1$ complex with $\lg \beta^{0}=2.6-3.2(\lg \beta=2.0-2.6, I=0.1 \mathrm{M})$. The influence of the moiety $\mathrm{R}$ on the $\mathrm{B}(\mathrm{OR})_{4}{ }^{-}$unit binding $\mathrm{Eu}(\mathrm{III})$ is secondary.

The application of different experimental approaches (Eu(III) complexation with inorganic and organic borates) and complementary spectroscopic methods provide a well secured range for the $\mathrm{Eu}(\mathrm{III})$-borate complexation.

Thus, our approach to use polyborates (Schott et al. ${ }^{9}$ ) and organoborates (this work) to determine Eu(III) complexation data allows for the conclusion that the $\mathrm{Eu}(\mathrm{III})$-monoborate also, which is not accessible for investigation directly, has a comparable complexation constant of $\lg \beta^{0}=2.6-3.2$.

In the context of deep geological disposal of radioactive wastes, the presence of dissolved borate compounds in a future nuclear waste repository should only slightly enhance the mobility of trivalent actinides and lanthanides in comparison with the much stronger complexing agents like hydroxide and carbonate.

\section{Acknowledgements}

This work was funded by the Federal Ministry of Economics and Energy (BMWi) under contract number 02E11021. The authors would like to thank A. Ritter (HZDR) for ICP-MS analyses. All the quantum chemical calculations were performed using PC-Farm Atlas at the "Zentrum für Informationsdienste und Hochleistungsrechnen" (ZIH) at the Technische Universität Dresden, Germany.

\section{References}

1 OECD/NEA, Physics and Safety of Transmutation Systems A Status Report, Paris, 2006.

2 W. Hummel, U. Berner, E. Curti, F. J. Pearson and T. Thoenen, Nagra/PSI Chemical Thermodynamic Data Base 01/01, NAGRA, Wettingen/Switzerland, 2002.

3 R. J. Silva, G. Bidoglio, M. H. Rand, P. B. Robouch, H. Wanner and I. Puigdomènech (OECD, NEA-TDB), Chemical Thermodynamics of Americium, North Holland, Amsterdam, 1995.

4 R. Guillaumont, T. Fanghänel, J. Fuger, I. Grenthe, V. Neck, D. A. Palmer and M. H. Rand (OECD, NEA-TDB), Update on the Chemical Thermodynamics of Uranium, Neptunium, Plutonium, Americium and Technetium, Elsevier, Amsterdam, 2003.

5 W. Hummel, G. Anderegg, I. Puigdomènech, L. Rao and O. Tochiyama (OECD, NEA-TDB), Chemical Thermodynamics of Compounds and Complexes of $\mathrm{U}, \mathrm{Np}, \mathrm{Pu}, \mathrm{Am}, \mathrm{Tc}, \mathrm{Se}, \mathrm{Ni}$ and Zr with Selected Organic Ligands, Elsevier, Amsterdam, 2005.
6 M. Borkowski, M. Richmann, D. T. Reed and Y. Xiong, Radiochim. Acta, 2010, 98, 577-582.

7 M. Altmaier, X. Gaona and T. Fanghänel, Chem. Rev., 2013, 113, 901-943.

8 M. J. Polinski, E. M. Villa and T. E. Albrecht-Schmitt, Coord. Chem. Rev., 2014, 266-267, 16-27.

9 J. Schott, J. Kretzschmar, M. Acker, S. Eidner, M. U. Kumke, B. Drobot, A. Barkleit, S. Taut, V. Brendler and T. Stumpf, Dalton Trans., 2014, 43, 11516-11528.

10 K. Hinz, M. Altmaier, X. Gaona, T. Rabung, D. Schild, M. Richmann, D. T. Reed, E. V. Alekseev and H. Geckeis, New J. Chem., 2015, 39, 849-859.

11 W. G. Woods, Environ. Health Perspect., 1994, 102(Suppl. 7), 5-11.

12 J. F. Lucchini, M. Borkowski, M. K. Richmann, S. Ballard and D. T. Reed, J. Alloys Compd., 2007, 444/445, 506-511.

13 D. A. Köse, B. Zümreoglu-Karan, T. Hökelek and E. Sahin, Inorg. Chim. Acta, 2010, 363, 4031-4037.

14 T. Oi, T. Takeda and H. Kakihana, Bull. Chem. Soc. Jpn., 1992, 65, 1903-1909.

15 C. C. Hinckley, J. Am. Chem. Soc., 1969, 91, 5160-5162.

16 B. C. Mayo, Chem. Soc. Rev., 1973, 2, 49-74.

17 J. D. Roberts, G. E. Hawkes, J. Husar, A. W. Roberts and D. W. Roberts, Tetrahedron, 1974, 30, 1833-1844.

18 A. F. Cockerill, G. L. O. Davies, R. C. Harden and D. M. Rackham, Chem. Rev., 1973, 73, 553-588.

19 M. J. Frisch, G. W. Trucks, H. B. Schlegel, G. E. Scuseria, M. A. Robb, J. R. Cheeseman, G. Scalmani, V. Barone, B. Mennucci, G. A. Petersson, H. Nakatsuji, M. Caricato, X. Li, H. P. Hratchian, A. F. Izmaylov, J. Bloino, G. Zheng, J. L. Sonnenberg, M. Hada, M. Ehara, K. Toyota, R. Fukuda, J. Hasegawa, M. Ishida, T. Nakajima, Y. Honda, O. Kitao, H. Nakai, T. Vreven, J. A. Montgomery Jr., J. E. Peralta, F. Ogliaro, M. Bearpark, J. J. Heyd, E. Brothers, K. N. Kudin, V. N. Staroverov, R. Kobayashi, J. Normand, K. Raghavachari, A. Rendell, J. C. Burant, S. S. Iyengar, J. Tomasi, M. Cossi, N. Rega, J. M. Millam, M. Klene, J. E. Knox, J. B. Cross, V. Bakken, C. Adamo, J. Jaramillo, R. Gomperts, R. E. Stratmann, O. Yazyev, A. J. Austin, R. Cammi, C. Pomelli, J. W. Ochterski, R. L. Martin, K. Morokuma, V. G. Zakrzewski, G. A. Voth, P. Salvador, J. J. Dannenberg, S. Dapprich, A. D. Daniels, Ö. Farkas, J. B. Foresman, J. V. Ortiz, J. Cioslowski and D. J. Fox, Gaussian 09, Revision A.02, Gaussian, Inc., Wallingford CT, 2009.

20 A. Bondi, J. Phys. Chem., 1964, 68, 441-451.

21 M. Dolg, H. Stoll, A. Savin and H. Preuss, Theor. Chim. Acta, 1989, 75, 173-194.

22 R. Krishnan, J. S. Binkley, R. Seeger and J. A. Pople, J. Chem. Phys., 1980, 72, 650-654.

23 A. Barkleit, S. Tsushima, O. Savchuk, J. Philipp, K. Heim, M. Acker, S. Taut and K. Fahmy, Inorg. Chem., 2011, 50, 5451-5459.

24 P. Gans, A. Sabatini and A. Vacca, Talanta, 1996, 43, 17391753.

25 A. Barkleit, M. Acker and G. Bernhard, Inorg. Chim. Acta, 2013, 394, 535-541. 
26 G. Tian, L. R. Martin and L. Rao, Inorg. Chem., 2010, 49, 10598-10605.

27 N. Rawat, R. S. Sharma, B. S. Tomar and V. K. Manchanda, Thermochim. Acta, 2010, 501, 13-18.

28 P. Gans, A. Sabatini and A. Vacca, Hyperquad Simulation and Speciation, Protonic Software, Leeds, 2009.

29 Lanthanide Probes in Life, Chemical and Earth Sciences Theory and Practice, ed. J.-C. G. Bünzli and G. R. Choppin, Elsevier Science B. V., Amsterdam, 1989.

30 C. A. Andersson and R. Bro, Chemom. Intell. Lab. Syst., 2000, 52, 1-4.

31 B. Drobot, R. Steudtner, J. Raff, G. Geipel, V. Brendler and S. Tsushima, Chem. Sci., 2015, 6, 964-972.

32 T. Saito, H. Sao, K. Ishida, N. Aoyagi, T. Kimura, S. Nagasaki and S. Tanaka, Environ. Sci. Technol., 2010, 44, 5055-5060.

33 R. M. Callejón, J. M. Amigo, E. Pairo, S. Garmón, J. A. Ocana and M. L. Morales, Talanta, 2012, 88, 456-462.

34 K. Ishida, T. Saito, N. Aoyagi, T. Kimura, R. Nagaishi, S. Nagasaki and S. Tanaka, J. Colloid Interface Sci., 2012, 374, 258-266.

35 P. Gans, A. Sabatini and A. Vacca, Hyperquad suite of programs, Protonic Software, Leeds, 2008.

36 A. Heller, A. Barkleit, H. Foerstendorf, S. Tsushima, K. Heim and G. Bernhard, Dalton Trans., 2012, 41, 1396913983.

37 A. Shokrollahi, M. Montazerozohori, T. Mehrpour, H. Tavallali, B. Z. Khafri and Z. Montaseri, Quim. Nova, 2013, 36, 1354-1359.

38 L. E. Santos-Figueroa, M. E. Moragues, M. M. M. Raposo, R. M. F. Batista, R. C. M. Ferreira, S. P. G. Costa, F. Sancenon, R. Martinez-Manez, J. Soto and J. V. Ros-Lis, Tetrahedron, 2012, 68, 7179-7186.

39 A. Günther and G. Bernhard, HZDR-IRE Annual Report 2012, Dresden, 2013, HZDR-030, ISSN 2191-8716.

40 C. W. Davies, Ion Association, Butterworths, London, 1962.

41 R. Corigli, F. Secco and M. Venturini, Inorg. Chem., 1982, 21, 2992-2998.

42 O. Lukkari and J. Tamminen, Finn. Chem. Lett., 1988, 15, 13-17.

43 M. L. S. Goncalves and A. M. Mota, Talanta, 1987, 34, 839847.

44 T. Paal and M. Mate, Magy. Kem. Foly., 1988, 94, 143-144.

45 S. Friedman, B. Pace and R. Pizer, J. Am. Chem. Soc., 1974, 96, 5381-5384.

46 S. H. Eberle and J. B. Schaefer, J. Inorg. Nucl. Chem., 1969, 31, 1523-1527.

47 S. Giroux, S. Aury, B. Henry and P. Rubini, Eur. J. Inorg. Chem., 2002, 5, 1162-1168.
48 N. Ingri, Acta Chem. Scand., 1962, 16, 439-448.

49 K. Yoshimura, Y. Miyazaki, F. Ota, S. Matsuoka and H. Sakashita, J. Chem. Soc., Faraday Trans., 1998, 94, 683689.

50 R. Pizer and P. J. Ricatto, Inorg. Chem., 1995, 34, 10071008.

51 A. Hertam, Diploma thesis, Freiberg University of Mining and Technology, 2011.

52 Y. Miyazaki, H. Matsuo, T. Fujimori, H. Takemura, S. Matsuoka, T. Okobira, K. Uezu and K. Yoshimura, Polyhedron, 2008, 27, 2785-2790.

53 Y. Miyazaki, T. Fujimori, H. Okita, T. Hirano and K. Yoshimura, Dalton Trans., 2013, 42, 10473-10486.

54 J. M. Coddington and M. J. Taylor, J. Coord. Chem., 1989, 20, 27-38.

55 Y. Miyazaki, K. Yoshimura, Y. Miura, H. Sakashita and K. Ishimaru, Polyhedron, 2003, 22, 909-916.

56 M. Van Duin, J. A. Peters, A. P. G. Kieboom and H. Van Bekkum, Tetrahedron, 1985, 41, 3411-3421.

57 A. Queen, Can. J. Chem., 1977, 55, 3035-3039.

58 R. Larsson and G. Nunziata, Acta Chem. Scand., 1972, 26, 1503-1509.

59 M. Mikesova and M. Bartusek, Chem. Zvesti, 1978, 32, 472477.

60 T. Paal and M. Mate, Magy. Kem. Foly., 1985, 91, 569-570.

61 R. Pizer and R. Selzer, Inorg. Chem., 1984, 23, 3023-3026.

62 R. Larsson and G. Nunziata, Acta Chem. Scand., 1970, 24, 2156-2168.

63 Y. Hasegawa, Y. Morita, M. Hase and M. Nagata, Bull. Chem. Soc. Jpn., 1989, 62, 1486-1491.

64 R. Pizer and P. J. Ricatto, Inorg. Chem., 1994, 33, 24022406.

65 A. Barkleit, J. Kretzschmar, S. Tsushima and M. Acker, Dalton Trans., 2014, 43, 11221-11232.

66 M. A. Gouveia and R. Guedes de Carvalho, J. Inorg. Nucl. Chem., 1966, 28, 1683-1688.

67 M. Van Duin, J. A. Peters, A. P. G. Kieboom and H. Van Bekkum, Tetrahedron, 1984, 40, 2901-2911.

68 R. Portanova, L. H. J. Lajunen, M. Tolazzi and J. Piispanen, Pure Appl. Chem., 2003, 75, 495-540.

69 M. J. Polinski, E. B. Garner, R. Maurice, N. Planas, J. T. Stritzinger, T. G. Parker, J. N. Cross, T. D. Green, E. V. Alekseev, S. M. Van Cleve, W. Depmeier, L. Gagliardi, M. Shatruk, K. L. Knappenberger, G. Liu, S. Skanthakumar, L. Soderholm, D. A. Dixon and T. E. Albrecht-Schmitt, Nat. Chem., 2014, 6, 387-392.

70 M. J. Polinski, S. Wang, J. N. Cross, E. V. Alekseev, W. Depmeier and T. E. Albrecht-Schmitt, Inorg. Chem., 2012, 51, 7859-7866. 